NBER WORKING PAPER SERIES

\title{
IDENTIFICATION AND ESTIMATION \\ OF DYNAMIC GAMES
}

\author{
Martin Pesendorfer \\ Philipp Schmidt-Dengler
}

Working Paper 9726

http://www.nber.org/papers/w9726

\section{NATIONAL BUREAU OF ECONOMIC RESEARCH 1050 Massachusetts Avenue Cambridge, MA 02138}

May 2003

\begin{abstract}
We are grateful to Nicholas Marchitto for his excellent research assistance, and we are particularly grateful to the Chamber of Business of Lower Austria for providing us with their membership data. An earlier version of the paper was circulated under the title "Identification and Estimation of Dynamic Entry Games." We thank Richard Blundell, Tilman Borgers, Hide Ichimura, Mireia Jofre-Bonet and seminar participants at UCL for helpful comments. Martin Pesendorfer thanks the NSF under grant SES 0214222 for financial support. The views expressed herein are those of the authors and not necessarily those of the National Bureau of Economic Research.
\end{abstract}

(C)2003 by Martin Pesendorfer and Philipp Schmidt-Dengler. All rights reserved. Short sections of text not to exceed two paragraphs, may be quoted without explicit permission provided that full credit including (C) notice, is given to the source. 
Identification and Estimation of Dynamic Games

Martin Pesendorfer and Philipp Schmidt-Dengler

NBER Working Paper No. 9726

May 2003

JEL No. L1, D43, D99

\section{$\underline{\text { ABSTRACT }}$}

This paper studies the identification problem in infinite horizon Markovian games and proposes a generally applicable estimation method. Every period firms simultaneously select an action from a finite set. We characterize the set of Markov equilibria. Period profits are a linear function of equilibrium choice probabilities. The question of identification of these values is then reduced to the existence of a solution to this linear equation system. We characterize the identification conditions. We propose a simple estimation procedure which follows the steps in the identification argument. The estimator is consistent, asymptotic normally distributed, and efficient.

We have collected quarterly time series data on pubs, restaurants, coffeehouses, bakeries and carpenters for two Austrian towns between 1982 and 2002. A dynamic entry game is estimated in which firms simultaneously decide whether to enter, remain active, or exit the industry. The period profit estimates are used to simulate the equilibrium behavior under a policy experiment in which a unit tax is imposed on firms deciding to enter the industry.

Martin Pesendorfer

Department of Economics

London School of Economics

London WC2A 2AE

United Kingdom

CEPR and NBER

m.pesendorfer@1se.ac.uk
Philipp Schmidt-Dengler

Department of Economics

Yale University

New Haven, CT 06520

philipp.schmidt-dengler@yale.edu 


\section{Introduction}

After the seminal papers by Bresnahan and Reiss (1987, 1990, 1991), equilibrium conditions of static games with binary actions have become a basic estimation tool in empirical industrial organization. The technique makes possible the inference of profit values and entry costs based on the number of active firms in the industry. Static entry models have been analyzed in a number of recent papers including Berry (1992), Davis (1999), Mazzeo (2002), Seim (2001) and Tamer (2003). See Reiss (1996) and Berry and Reiss (2002) for surveys of the literature. A shortcoming of this literature is that dynamic considerations are left aside and a static view of the world is adopted.

This paper studies the identification problem of infinite horizon Markovian games and proposes a generally applicable estimation method for dynamic games. Every period each firm privately observes a profitability shock drawn from a known distribution function. Firms simultaneously choose an action from a finite set. In our application, the firms decide whether to enter, to remain active, or to exit the industry. The dynamic game permits decisions to be a function of observable state variables. Firms make forward looking decisions taking into account the effect of future entry and demand on future profits. The dynamic formulation has at least three advantages over the static model commonly used in the literature: (i) it allows distinct period payoffs as a function of state variables; (ii) contemporaneous demand and state variables determine whether entry takes place; and (iii) explicit information in the timing of actions is exploited. The increased richness of our model permits us to infer a larger set of parameters.

The main contribution of the paper is twofold: First, we show new identification results for dynamic games. We characterize conditions under which the period payoffs can be identified. The identification arguments are based on a sufficiently rich time-series data on observed choices.

Second, we propose a computationally simple estimation method generally applicable for dynamic games. The estimation method is similar to Jofre-Bonet and Pesendorfer (2002) but considers finite action games instead of continuous choice games. The choice probabilities are estimated using maximum likelihood. The period payoffs are inferred by using the equilibrium conditions of the dynamic game. The estimator is consistent, asymptotic normally distributed, and efficient.

The main idea behind this paper stems from the following observation: In finite action games with private information, there exists a type that is exactly indifferent between two alternative actions. For this type, the continuation value of one action must equal the continuation value of the alternative action. The indifferent type condition is satisfied at every state vector yielding an equation system with as many equations as there are states. The equation system stemming from the indifference conditions permits us to adopt a similar estimation technique as to that in 
continuous choice dynamic games. The indifferent type is not observed but can be inferred from the observed choices. Further, for each state variable, the indifference condition is a linear equation in period profits. This follows from the fact that the value function is linear in period payoffs. The linearity substantially simplifies the identification and estimation problem. Based on the linearity, we can express the parameters of the model as an explicit function of the choice probabilities. The identification question is then reduced to the existence of a unique solution to the linear equation system. In addition, the set of indifference conditions enables us to numerically calculate Markov equilibria of finite action games in a simple way.

We apply the proposed method to data consisting of quarterly time series observations regarding the identity of active firms in a number of industries for two Austrian cities between 1982 and 2002. In addition, we use gross domestic product time series data. The estimation proceeds as follows: First, a probit model is estimated. The dependent variable is an indicator variable whether the firm is active in a period. The explanatory variables are the state variables including an indicator of whether the firm was active in the preceding period, the number of other active firms in the preceding period, the level of gross domestic product, and interaction terms between these variables. We assume that gross domestic product evolves deterministically. We then construct the transition probability matrix of state variables using the probit estimates.

We infer the period profit values based on the equilibrium condition for the indifferent type. We illustrate the simplicity of the estimation approach, discuss the goodness of fit of our estimates, and assess properties of the equilibrium. Finally, we conduct a policy experiment in which a unit tax is imposed on firms deciding to enter the industry.

There is a small empirical literature on dynamic games including Aguirregabiria and Mira (2002), Jofre-Bonet and Pesendorfer (2000, 2002) and Pakes and Berry (2002). Aguirregabiria and Mira (2002) consider a two-stage estimation approach for dynamic games with finite actions. They show that, after substituting the first stage choice probabilities and obtaining an expression for the value function, the optimality conditions of the discrete game can be written as inequalities in the parameters of the model. In the second stage, Aguirregabiria and Mira propose a pseudo maximum likelihood estimator in which the likelihood defined by those inequalities is maximized. Simulation is used in the second stage to reduce the computational complexity of the estimator. Pakes and Berry (2002) propose two estimators for dynamic entry games: A nested fixed point estimator similar to Rust (1994), and a two stage estimator in which a pseudo likelihood is estimated in the second stage, similarly to Aguirregabiria and Mira (2002). In contrast to these approaches, the estimator proposed in this paper dispenses entirely with the second stage maximum likelihood estimation, or nested fixed point estimation. Instead, an efficient and computationally simple estimator is proposed 
by expressing the parameters of the model as an explicit function of the choice probabilities.

Our model formulation and estimation approach is most closely related to Jofre-Bonet and Pesendorfer $(2000,2002)$. Jofre-Bonet and Pesendorfer consider an infinite horizon Markovian bidding game with idiosyncratic cost shocks under the presence of capacity constraints. Estimation proceeds in two stages: In the first stage, the choice probabilities are estimated using the observed bid data. In the second stage, the costs are inferred based on the first order condition of optimally chosen bids. Jofre-Bonet and Pesendorfer (2000, 2002) show that the first order condition of the dynamic game is a linear equation in unknown costs.

The paper is organized as follows: Section 2 describes the dynamic game with a finite action space. Section 3 characterizes properties of the equilibrium. Section 4 presents the identification results. Section 5 proposes the estimator. Section 6 describes the data and gives some descriptive statistics. Section 7 reports the estimation results. Section 8 ilustrates the long run payoffs and assesses a policy experiment in which a unit tax is imposed on firms deciding to enter. Section 9 concludes.

\section{Model}

This section describes the elements of the model. We describe the sequencing of events, the period game, the transition function, the payoffs, the strategies and the equilibrium concept.

We consider a dynamic game with discrete time, $t=1,2 \ldots, \infty$. The set of firms is denoted by $\mathbf{N}=\{1, \ldots, N\}$ and a typical firm is denoted by $i \in \mathbf{N}$. The number of firms is fixed and does not change over time. Every period the following events take place:

A state vector is publicly observed. Each firm is endowed with a state variable $s_{i}^{t} \in S_{i}=$ $\{1, \ldots, L\}$. The vector of all firms' state variables is denoted by $s^{t}=\left(s_{1}^{t}, \ldots, s_{N}^{t}\right) \in S=\times_{j=1}^{N} S_{j}$. Sometimes we use the notation $s_{-i}^{t}=\left(s_{1}^{t}, \ldots, s_{i-1}^{t}, s_{i+1}^{t}, \ldots, s_{N}^{t}\right) \in S_{-i}$ to denote the vector of states by firms other than firm $i$. The cardinality of the state space $S$ equals $m_{s}=L^{N}$.

Each firm i privately observes a $K$ dimensional real valued profitability shock $\varepsilon_{i}^{t}=\left(\varepsilon_{i}^{t 1}, \ldots, \varepsilon_{i}^{t K}\right) \in$ $\Re^{K}$. The shock is not observed by other firms. The shock $\varepsilon_{i}^{t k}$ is drawn independently from the strict monotone and continuous distribution function $F$. Independence of $\varepsilon_{i}^{t}$ from the state variables is an important assumption, since it allows us to adopt the Markov dynamic decision framework. For a discussion of the independence assumption in Markovian decision problems see Rust (1994). We assume that $E\left[\varepsilon_{i}^{t k} \mid \varepsilon_{i}^{t k} \geq \varepsilon\right]$ exists for all $\varepsilon$, to ensure that the expected period return exists.

Actions: Each firm decides which action to take, $a_{i}^{t} \in A_{i}=\{0,1, \ldots, K\}$. All $N$ firms, including firms not active in the last period, make their decisions simultaneously. The actions are taken after 
firms observe the state and their idiosyncratic productivity shock. An action profile $a^{t}$ denotes the vector of joint actions in period $t, a^{t}=\left(a_{1}^{t}, \ldots, a_{N}^{t}\right) \in A=\times_{j=1}^{N} A_{j}$. The cardinality of the action space $A$ equals $m_{a}=(K+1)^{N}$.

The transition of the state variables is described by a probability density function $g: A \times S \times S \longrightarrow$ $[0,1]$ where a typical element $g\left(a^{t}, s^{t}, s^{t+1}\right)$ equals the probability that state $s^{t+1}$ is reached when the current action profile and state are given by $\left(a^{t}, s^{t}\right)$. We require $\sum_{s^{\prime} \in S} g\left(a, s, s^{\prime}\right)=1$ for all $(a, s) \in A \times S$. We frequently use the symbol $G$ to denote the $\left(m_{a} \cdot m_{s}\right) \times m_{s}$ dimensional transition matrix in which column $s^{\prime} \in S$ consists of the vector of probabilities $\left[g\left(a, s, s^{\prime}\right)_{a \in A, s \in S}\right]$.

The period payoff of firm $i$ is collected at the end of the period after all actions are observed. The period payoff of firm $i$ consists of the profit realization and the profitability shock realization. We can write period payoffs as a real valued function defined on $A \times S \times \Re^{K}$ and given by:

$$
\pi_{i}\left(a^{t}, s^{t}\right)+\sum_{k=1}^{K} \varepsilon_{i}^{t k} \cdot \mathbf{1}_{\left\{a_{i}^{t}=k\right\}}
$$

where $\mathbf{1}_{a}$ equals one if event $a$ occurs and zero otherwise; the profit $\pi$ depends on the action profile of firms and the state vector. We assume that profits are bounded, $\left|\pi_{i}().\right|<\infty$ for all $i$. We sometimes use the symbol $\Pi_{i}$ to denote the $\left(m_{a} \cdot m_{s}\right) \times 1$ dimensional period profit vector defined by $\Pi_{i}=\left[\pi_{i}(a, s)_{a \in A, s \in S}\right]$. The profitability shock affects actions $k>0$ only. The assumption that action 0 is not affected by the profitability shock is not restrictive as only the payoff difference between alternative actions matters.

Firms discount future payoffs with the common discount factor $\beta<1$. The game payoff of firm $i$ equals the sum of discounted period payoffs.

Following Maskin and Tirole (1994, 2001), we consider sequential equilibria in Markovian strategies $a_{i}\left(\varepsilon_{i}^{t} ; s^{t}\right)$. A strategy for firm $i$ is a function of the firm specific profitability shock and the state variables. The assumption that the profitability shock is independently distributed allows us to write the probability of observing action profile $a^{t}$ as $\operatorname{Pr}\left(a^{t} \mid s^{t}\right)=\operatorname{Pr}\left(a_{1}^{t} \mid s^{t}\right) \cdots \operatorname{Pr}\left(a_{N}^{t} \mid s^{t}\right)$. The Markovian assumption allows us to abstract from calendar time and subsequently we omit the time superscript.

Symmetry: We are sometimes interested in symmetric payoffs and strategies. Symmetry requires identical payoff vectors, $\Pi_{i}=\Pi$ for all $i$, and identical strategies for all $i$. Asymmetries between firms are then captured in the state variables only. The symmetry assumption reduces the dimensionality of the problem, which can simplify calculations.

The discounted sum of future payoffs for firm $i$ consists of two elements: The period profit and 
the profitability shock. In value function notation, the discounted sum is given by:

$$
\begin{aligned}
W_{i}\left(s, \varepsilon_{i}\right)= & \max _{a_{i} \in A_{i}} \sum_{a_{-i} \in A_{-i}} \operatorname{Pr}\left(a_{-i} \mid s\right)\left[\pi_{i}\left(a_{-i}, a_{i}, s\right)+\sum_{k=1}^{K} \varepsilon_{i}^{k} \cdot \mathbf{1}_{\left\{a_{i}=k\right\}}\right. \\
& \left.+\beta E_{\varepsilon} \sum_{s^{\prime} \in S} g\left(a, s, s^{\prime}\right) W_{i}\left(s^{\prime}, .\right)\right]
\end{aligned}
$$

where $\operatorname{Pr}\left(a_{-i} \mid s\right)$ denotes the conditional probability that firms $-i$ choose an action profile $a_{-i}$ conditional on state $s$, and $E_{\varepsilon}$ denotes the expectation operator with respect to the firm specific productivity shock. The finiteness of the action and the state spaces guarantees the existence of the value function $W_{i}$, see Rust (1994).

Ex ante value function: We use the ex-ante value function, which is defined as the value function in expression (1) before firm-specific shocks are observed and actions are taken, $V_{i}(s)=E_{\varepsilon} W_{i}(s, \varepsilon)$. Taking the expectation with respect to $\varepsilon$ inside the sum yields:

$$
V_{i}(s)=\sum_{a \in A} \operatorname{Pr}(a \mid s)\left[\pi_{i}(a, s)+\beta \sum_{s^{\prime} \in S} g\left(a, s, s^{\prime}\right) V_{i}\left(s^{\prime}\right)\right]+\sum_{k=1}^{K} E_{\varepsilon}\left[\varepsilon_{i}^{k} \mid a_{i}=k\right] \cdot \operatorname{Pr}\left(a_{i}=k \mid s\right)
$$

Equation (2) is satisfied at every state vector $s \in S$. Since the state space is finite, we can express it as a matrix equation:

$$
V_{i}=P \Pi_{i}+D_{i}+\beta P G V_{i}
$$

where $P$ is the $m_{s} \times\left(m_{a} \cdot m_{s}\right)$ dimensional matrix consisting of choice probability $\operatorname{Pr}(a \mid s)$ in row $s$ column $(a, s)$, and zeros in row $s$ column $\left(a, s^{\prime}\right)$ with $s^{\prime} \neq s ; D_{i}=\left[D_{i}(s)\right]_{s \in S}$ is the $m_{s} \times 1$ dimensional vector of expected profitability shocks with element $D_{i}(s)=\sum_{k=1}^{K} E_{\varepsilon}\left[\varepsilon_{i}^{k} \mid a_{i}=k\right]$. $\operatorname{Pr}\left(a_{i}=k \mid s\right) ; V_{i}=\left[V_{i}(s)\right]_{s \in S}$ is the $m_{s} \times 1$ dimensional vector of expected discounted sum of future payoffs; and $G$ denotes the $\left(m_{a} \cdot m_{s}\right) \times m_{s}$ dimensional transition matrix defined above. Notice that this matrix equation is a recursive equation in $V_{i}$. Let $I_{s}$ denote the $m_{s}$ dimensional identity matrix. By the dominant diagonal property, the matrix $\left[I_{s}-\beta P G\right]$ is invertible. We can rewrite the recursive equation to obtain an explicit expression for $V_{i}$ :

$$
V_{i}=\left[I_{s}-\beta P G\right]^{-1}\left[P \Pi_{i}+D_{i}\right]
$$

Equation (3) provides an expression for the equilibrium ex ante value function. The terms on the right hand side are the discount factor, the equilibrium choice probability matrix, the state transition matrix, the period return function, and the equilibrium expected profitability shocks.

Notice, that the value function is a linear function in the period payoffs. The linearity property will help us examine the properties of the equilibrium choices in the next section. 


\section{Equilibrium Characterization}

This section characterizes properties of the dynamic equilibrium. It studies properties of the equilibrium decision rule, the equilibrium discounted sum of payoffs and the equilibrium choice probabilities. We show that the equilibrium decision rule is characterized by an $m_{s} \cdot K$ equation system. We conclude the section with remarks on the existence and multiplicity of equilibria.

We begin the analysis with a characterization of the equilibrium decision rule. The following Proposition states a property of equilibrium strategies:

Proposition 1 In any Markov equilibrium for any $s \in S$ and for all $i \in N$ there exists an $\bar{\varepsilon}_{i}(s)=$ $\left(\bar{\varepsilon}_{i}^{1}(s), \ldots, \bar{\varepsilon}_{i}^{K}(s)\right)^{\prime}$ such that

$$
a_{i}\left(\varepsilon_{i}, s\right)=\left\{\begin{array}{cc}
k & \text { if } \varepsilon_{i}^{k}>\bar{\varepsilon}_{i}^{k}(s) \text { and for all } k^{\prime} \neq k: \varepsilon_{i}^{k}-\varepsilon_{i}^{k^{\prime}}>\bar{\varepsilon}_{i}^{k}(s)-\bar{\varepsilon}_{i}^{k^{\prime}}(s) ; \\
0 & \text { if } \varepsilon_{i}^{k}<\bar{\varepsilon}_{i}^{k}(s) \text { for all } k .
\end{array}\right.
$$

All proofs are given in the appendix. Proposition 1 establishes that the equilibrium decision on whether to adopt action $k$ or not is monotone in the profitability shock $\varepsilon_{i}^{k}$.

The statement in the Proposition is readily illustrated for an action pair $(k, 0)$ for a typical firm $i$. It says that, for any state vector, there exists a type $\bar{\varepsilon}^{k}$ that is indifferent between actions $k$ and 0 . The monotonicity property follows from the assumption that the payoff function is additive in the private profitability shock $\varepsilon^{k}$. If there exists a point $\bar{\varepsilon}^{k}$ such that a firm of type $\bar{\varepsilon}^{k}$ is indifferent between actions $k$ and 0 , then any type with a smaller profitability shock, $\varepsilon^{k}<\bar{\varepsilon}^{k}$, will prefer action 0 . On the other hand, any type with a higher profitability shock, $\varepsilon^{k}>\bar{\varepsilon}^{k}$, will prefer action $k$. The reason is that the current period payoff for an active firm is additive in $\varepsilon^{k}$, while the future payoffs and the current period payoff for a firm choosing action 0 are unaffected by $\varepsilon^{k}$. The point $\bar{\varepsilon}^{k}$ exists, since the support of $\varepsilon^{k}$ is unbounded, while the period return $\Pi$, and the value function are bounded.

Indifference equation: The indifferent type $\bar{\varepsilon}_{i}^{k}$ receives the same expected discounted sum of payoffs under action $k$ as under action 0 . This leads to the indifference equation:

$$
\begin{aligned}
& \sum_{a_{-i} \in A_{-i}} \operatorname{Pr}\left(a_{-i} \mid s\right) \cdot\left[\pi_{i}\left(a_{-i}, k, s\right)+\beta \sum_{s^{\prime} \in S} g\left(a_{-i}, k, s, s^{\prime}\right) V_{i}\left(s^{\prime}\right)\right]+\bar{\varepsilon}_{i}^{k}(s) \\
= & \sum_{a_{-i} \in A_{-i}} \operatorname{Pr}\left(a_{-i} \mid s\right) \cdot\left[\pi_{i}\left(a_{-i}, 0, s\right)+\beta \sum_{s^{\prime} \in S} g\left(a_{-i}, k, s, s^{\prime}\right) V_{i}\left(s^{\prime}\right)\right]
\end{aligned}
$$

Equation (5) is a necessary equilibrium condition that must be satisfied at every state $s \in S$ and for every action $k=1, \ldots, K$ yielding a total of $m_{s} \cdot K$ equations with $m_{s} \cdot K$ indifferent types, one for each possible state and action. We may compactly write equation (5) in matrix form. Let 
$\bar{\varepsilon}_{i}=\left[\bar{\varepsilon}_{i}^{k}(s)\right]_{s \in S, k=1, \ldots K}$ be the $\left(m_{s} \cdot K\right) \times 1$ dimensional vector of indifferent types; let $P_{-i}$ be the $m_{s} \times\left((K+1)^{N-1} \cdot m_{s}\right)$ dimensional matrix consisting of choice probability $\operatorname{Pr}\left(a_{-i} \mid s\right)$ in row $s$ column $\left(a_{-i}, s\right)$, and zeros in row $s$ column $\left(a_{-i}, s^{\prime}\right)$ with $s^{\prime} \neq s$; and define the $\left(m_{s} \cdot K\right) \times\left(m_{a} \cdot m_{s}\right)$ dimensional matrix $P_{i}(\bar{\varepsilon})$ as:

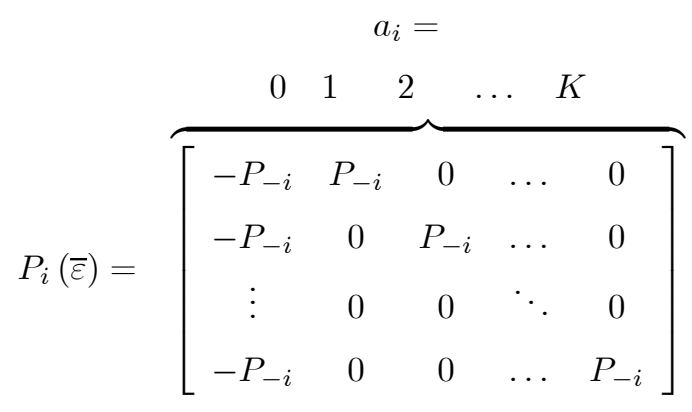

We can re-state equation (5) as:

$$
P_{i}(\bar{\varepsilon}) \Pi_{i}+\beta P_{i}(\bar{\varepsilon}) G V_{i}+\bar{\varepsilon}_{i}=0
$$

Substituting equation (3) into equation (6), leads us to the following result:

Proposition 2 In any Markov equilibrium for all $i \in N$ there exists $\bar{\varepsilon}_{i}$ such that:

$$
\left[P_{i}(\bar{\varepsilon})+\beta P_{i}(\bar{\varepsilon}) G\left[I_{s}-\beta P(\bar{\varepsilon}) G\right]^{-1} P(\bar{\varepsilon})\right] \Pi_{i}+\beta P_{i}(\bar{\varepsilon}) G\left[I_{s}-\beta P(\bar{\varepsilon}) G\right]^{-1} D_{i}(\bar{\varepsilon})+\bar{\varepsilon}_{i}=0 .
$$

Conversely, any $\bar{\varepsilon}=\left(\bar{\varepsilon}_{1}, \ldots, \bar{\varepsilon}_{N}\right)$ that satisfies equation (7) can be extended to a Markov equilibrium.

The above Proposition characterizes the set of equilibria. It provides a necessary and sufficient condition for any Markov equilibrium. It gives a system of $m_{s} \cdot K \cdot N$ indifference equations characterizing the $m_{s} \cdot K \cdot N$ equilibrium indifference points $\bar{\varepsilon}$. The necessity part stems from the indifference condition which says that, for the indifferent type, the continuation value when taking action $k$ is exactly equal to the continuation value when taking action 0 . The sufficiency part in the Proposition is established by showing that any $\bar{\varepsilon}$ that satisfies equation (7) can be extended to construct a decision rule that constitutes a Markov equilibrium.

Equation (7) in Proposition 2 is a linear equation in the parameter $\Pi_{i}$. The linearity property will play a central role in the identification and estimation section.

Next, we provide a few remarks on the existence, computation and multiplicity of equilibria. The following theorem establishes that an equilibrium exists.

Theorem 1 A Markov equilibrium exists. 
The theorem follows from Brouwer's fixed point theorem. Equation (7) gives us a continuous function from a bounded subset of $\Re^{m_{s} \cdot K \cdot N}$ onto itself. By Brouwer's theorem it has a fixed point $\bar{\varepsilon}$.

Proposition 2 and Theorem 1 enable us to calculate equilibria numerically. They show that the equilibrium calculation is reduced to a fixed point problem in $\Re^{m_{s} \cdot K \cdot N}$, which is solvable even for non-trivial $m_{s}, K$ and $N$. Backwards solving algorithms, which calculate a new optimal policy and value function at each step of the iteration, are computationally complex, as is shown in Pakes and McGuire (2001). Proposition 2 shows that the space of indifferent types gives an equivalent representation of equilibria which facilitates the computation considerably. Hence, it is not needed to determine the optimal decision rule and value function at every step of the iteration.

A remaining issue is whether the equilibrium is unique or not. The following example illustrates that more than one equilibrium can exist.

Multiplicity of Equilibria: Suppose the industry consists of two firms. States and actions are binary. Period profits do not depend on state variables. Monopoly profits equal $\frac{3}{2}$ and duopoly profits equal $-\frac{3}{2}$. The profitability shock is drawn from a standard normal distribution function. Firms decide whether to be active or inactive. Then, there exist multiple equilibria. We describe three symmetric equilibria. Two equilibria have the following feature along the equilibrium path: Only one firm is active in any period with high probability. This arises due to the positive monopoly and negative duopoly payoffs. In the first equilibrium the identity of the active firm changes every period. The active firm becomes inactive and the inactive firm becomes active. In the second equilibrium, the active firm remains active and the inactive firm remains inactive. The third equilibrium differs. On its path, each firm has a fifty percent chance of being active. ${ }^{1}$ The equilibria are robust to parameter perturbations. Profit values with distinct values for different states - but small differences in the state dimension - and a positive but small discount factor yield equilibria with the same qualitative equilibrium behavior.

Symmetry: We conclude the section with a discussion of the symmetry assumption which is assumed in the empirical section. Symmetry requires identical payoff vectors $\Pi_{i}=\Pi$ and identical decision rules. It can be verified that the above arguments remain valid under the symmetry restriction which leads us to the following Corollary:

\footnotetext{
${ }^{1}$ The equilibrium strategies are the following: (i) $a(1,1, \varepsilon)=a(0,0, \varepsilon)=1$ if and only if $\varepsilon>0, a(1,0, \varepsilon)=1$ if and only if $\varepsilon>1.08$, and $a(0,1, \varepsilon)=1$ if and only if $\varepsilon>-1.08$

(ii) $a(1,1, \varepsilon)=a(0,0, \varepsilon)=1$ if and only if $\varepsilon>0, a(1,0, \varepsilon)=1$ if and only if $\varepsilon>-1.08$, and $a(0,1, \varepsilon)=1$ if and only if $\varepsilon>1.08$

(iii) $a(1,1, \varepsilon)=a(0,0, \varepsilon)=1$ if and only if $\varepsilon>0, a(1,0, \varepsilon)=1$ if and only if $\varepsilon>0$, and $a(0,1, \varepsilon)=1$ if and only if $\varepsilon>0$.
} 
Corollary 1 Suppose $\Pi_{i}=\Pi$.

(i) A symmetric Markov equilibrium exists.

(ii) For any symmetric Markov equilibrium there exists an $\bar{\varepsilon}_{1}$ such that $\bar{\varepsilon}=\left(\bar{\varepsilon}_{1}, \ldots, \bar{\varepsilon}_{1}\right)$ satisfies

$$
\left[P_{1}(\bar{\varepsilon})+\beta P_{1}(\bar{\varepsilon}) G\left[I_{s}-\beta P(\bar{\varepsilon}) G\right]^{-1} P(\bar{\varepsilon})\right] \Pi+\beta P_{1}(\bar{\varepsilon}) G\left[I_{s}-\beta P(\bar{\varepsilon}) G\right]^{-1} D\left(\bar{\varepsilon}_{1}\right)+\bar{\varepsilon}_{1}=0 .
$$

Conversely, any $\bar{\varepsilon}=\left(\bar{\varepsilon}_{1}, \ldots, \bar{\varepsilon}_{1}\right)$ that satisfies equation (8) can be extended to a symmetric Markov equilibrium.

The symmetry assumption reduces the number of equations in (7). The reduction in dimension reduces the complexity of the problem which may facilitate the numerical calculation of equilibria. Additionally, symmetry places a number of restrictions on the payoff vector $\Pi$ which can be useful in the empirical analysis.

So far we have characterized several qualitative features of the equilibrium. In addition, we provided a simple characterization of the equilibrium choice probabilities in form of an equation system that can be solved numerically. Finally, we illustrated that the analysis remains valid under the symmetry restriction. Next, we use the necessary and sufficient equilibrium condition (7) which is a linear equation in period payoffs to address the question of identification.

\section{Identification}

This section studies identification conditions of the underlying model parameters which are the distribution of profitability shocks $F$, the discount factor $\beta$, and the period profit vector $\Pi$. We provide conditions that allow us to find a unique set of parameters that rationalizes the observed choices. We conclude the section with a discussion of the identifying conditions in symmetric entry models. These conditions are imposed in our empirical application.

We assume that a time-series sample of choices and states is available. The sample is sufficiently large to characterize the equilibrium choice probabilities.

Assumption 1: We observe data $\left(a^{t}, s^{t}\right)_{t=1}^{T}$ which permit us to characterize the choice probabilities $\operatorname{Pr}(a \mid s)$ and the transition probabilities $g\left(a, s, s^{\prime}\right)$ for any $s, s^{\prime} \in S, a \in A$.

Notice that we consider a time-series data set from one industry at a time. Hence, the choice probabilities characterize a single equilibrium. ${ }^{2}$

The potential number of firms may not be known in some applications. This may arise if firms are not observed when inactive. Yet, if there is at least one action in which the firm is observed,

\footnotetext{
${ }^{2}$ Identification of static entry models based on a cross-section data set is considered in Tamer (2003).
} 
then the potential number of firms is identified. To see this, notice that every period every firm has a positive probability of selecting any action. This probability is bounded away from zero. Thus, eventually, all potential firms are observed. The potential number of firms equals the maximum number of observed firms.

The vector of indifferent types $\bar{\varepsilon}$ is not known. Proposition 1 gives a relationship between the vector of indifferent types and the equilibrium actions. If the distribution $F$ is known, then the relationship in Proposition 1 gives an equation characterizing choice probabilities in terms of the vector of indifferent types. The following Lemma states that the equation has a unique solution. The Lemma is due to Hotz and Miller (1993).

Lemma 1 Suppose $F$ is known. Suppose there exists a $\delta>0$ such that $\operatorname{Pr}\left(a_{i}=k \mid s\right)>\delta$ for all $i \in N, k \in A_{i}, s \in S$. Then for all $i \in N, s \in S$ there exists a unique vector $\bar{\varepsilon}_{i}(s)$ that solves the following $K$ equations, one for every action $k=1, \ldots, K$, given by:

$$
\operatorname{Pr}\left(a_{i}=k \mid s\right)=\operatorname{Pr}\left(\varepsilon_{i}^{k}>\bar{\varepsilon}_{i}^{k}(s) \text { and for all } k^{\prime} \neq k: \varepsilon_{i}^{k}-\varepsilon_{i}^{k^{\prime}}>\bar{\varepsilon}_{i}^{k}(s)-\bar{\varepsilon}_{i}^{k^{\prime}}(s)\right)
$$

The Lemma states that the indifferent types can be uniquely recovered from the choice probabilities provided $F$ is known. The Lemma is easily illustrated for binary action spaces. With binary actions equation (9)can be re-written to obtain a unique and explicit expression for the indifferent type given by:

$$
\bar{\varepsilon}_{i}^{1}(s)=F^{-1}\left(\operatorname{Pr}\left(a_{i}=0 \mid s\right)\right) .
$$

With the indifferent types recovered, we can infer the vector of ex ante expected profitability shocks by using Proposition 1, as:

$$
D_{i}(s)=\sum_{k=1}^{K} \int_{\bar{\varepsilon}_{i}^{k}(s)}^{\infty} \varepsilon^{k} \prod_{k^{\prime} \geq 1, k^{\prime} \neq k} F\left(\varepsilon^{k}+\bar{\varepsilon}^{k^{\prime}}-\bar{\varepsilon}^{k}\right) f\left(\varepsilon^{k}\right) d \varepsilon^{k} .
$$

With the choice probabilities, the transition probabilities and indifferent types at hand, all the coefficients entering equation (7) are known. Since equation (7) is a necessary and sufficient equilibrium condition, it can be used to infer period payoffs. Next, we discuss in some detail what conditions are required to make this inference possible.

The following Proposition provides a negative identification result.

Proposition 3 (i) The parameters $\left(F, \beta, \Pi_{1}, \ldots, \Pi_{N}\right)$ are not identified.

(ii) For given $F$, the parameters $\left(\beta, \Pi_{1}, \ldots, \Pi_{N}\right)$ are not identified.

(iii) For given $(F, \beta)$, the parameters $\left(\Pi_{1}, \ldots, \Pi_{N}\right)$ are not identified. 
The Proposition says that the model is not identified. The non-identification result is similar in spirit to results obtained in the single agent dynamics literature, see Rust (1994) and Magnac and Thesmar (2002). Part (i) says that in the absence of the knowledge of the distribution function $F$, the vector $\bar{\varepsilon}$ is not determined. Hence, none of the elements in equation (7) are known and the model is clearly not identified. The non-identification of the distribution function $F$ is closely related to the assumption of a finite action space. When the action space is an interval and the profit function is known, then $F$ can be identified, as is shown in Jofre-Bonet and Pesendorfer (2002). A parametric assumption on the distribution function $F$ is not enough, as can be seen from equation (7). Assuming that profitability shocks are normally distributed with mean zero and standard deviation $\sigma$ amounts to re-scaling the matrix $\Pi$ by the standard deviation $\sigma$. Hence, the standard deviation $\sigma$ is not identified.

Parts (ii) and (iii) take the distribution function $F$ as given. They show that the model's remaining parameters are not identified. The reason is that equation (7) has $K \cdot L^{N} \cdot N$ equations while the parameter vector has $(K+1)^{N} \cdot L^{N} \cdot N+1$ elements. Hence, even if in addition to $F$ the parameter $\beta$ is fixed, the remaining parameters are not identified.

Proposition 3 establishes the need to impose identifying restrictions. We proceed by fixing the distribution function $F$ and the discount parameter $\beta$ and discussing the identifying restrictions on the profit vector. In our application, we assume $F$ is the standard normal distribution function. Recall that equation (7) is linear in the profit parameter vector $\Pi_{i}$. With a known distribution function $F$ and a given discount parameter $\beta$, the question of identification of $\Pi_{i}$ is then reduced to the question of the existence of a unique solution to the linear equation system. In economic applications it can be verified whether the restrictions of the model yield a unique solution. We next discuss some restrictions for the single agent and multi agent case that guarantee identification.

In the single agent case, for a fixed discount parameter $\beta$, the rank of the matrix premultiplying the profit parameter vector in equation (7) is at most $K \cdot L$ as there are $K \cdot L$ equations. At least $L$ restrictions on profits are required as the profit parameter vector has $(K+1) \cdot L$ parameters. In economic applications it is assumed that the profit value for one action, say action zero, is fixed exogenously for every state, see Magnac and Thesmar (2002).

In the multi agent case, for a fixed discount parameter $\beta$ and for every firm $i$, the rank of the matrix premultiplying the profit parameter vector $\Pi_{i}$ in equation (7) is at most $K \cdot L^{N}$ as there are $K \cdot L^{N}$ equations. The profit parameter vector $\Pi_{i}$ has $(K+1)^{N} \cdot L^{N}$ parameters. Hence, at least $\left((K+1)^{N}-K\right) \cdot L^{N}$ restrictions on profits are required for every firm. We next state two restrictions for the multi agent case. We impose these restrictions in the estimation. 
Restriction (R1) says that period profits do not depend on the state variables of other firms:

$$
\pi_{i}\left(a_{i}, a_{-i}, s_{i}, s_{-i}\right)=\bar{\pi}_{i}\left(a_{i}, a_{-i}, s_{i}\right) \quad \text { for all } a \in A, s \in S
$$

for some $\left((K+1)^{N} \cdot L\right) \times 1$ dimensional vector $\bar{\Pi}_{i}=\left[\bar{\pi}_{i}\left(a_{i}, a_{-i}, s_{i}\right)\right]_{\left(a_{i}, a_{-i}, s_{i}\right) \in A_{i} \times A_{-i} \times S_{i}}$. Restriction $(R 1)$ fixes $(K+1)^{N} \cdot\left(L^{N}-L\right)$ profit parameters. Restriction $(R 1)$ is satisfied in games with adjustment costs such as entry or investment games.

Restriction (R2) says that period profits under action $a_{i}=0$ are fixed exogenously for every state $s_{i}$ and action profile $a_{-i}$ :

$$
\bar{\pi}_{i}\left(0, a_{-i}, s_{i}\right)=b_{i}\left(a_{-i}, s_{i}\right) \quad \text { for all } a_{-i} \in A_{-i}, s_{i} \in S_{i}
$$

for some $\left((K+1)^{N-1} \cdot L\right) \times 1$ dimensional exogenous vector $b_{i}$. Restriction $(R 2)$ fixes $(K+1)^{N-1} \cdot L$ profit parameters. Restriction $(R 2)$ is satisfied in games in which one action, say action inactivity, implies zero profits.

Restrictions $(R 1)$ and $(R 2)$ can be imposed in equation (7). Let $\bar{X}_{i}$ denote the restricted matrix of dimension $\left(K \cdot L^{N}\right) \times\left(K \cdot(K+1)^{N-1} \cdot L\right)$ which is obtained by summing columns in the unrestricted matrix $X_{i}=P_{i}+\beta P_{i} G\left[I_{s}-\beta P G\right]^{-1} P$ in equation (7) which are associated with identical profit values $\bar{\pi}_{i}\left(a_{i}, a_{-i}, s_{i}\right)$ for $a_{i}>0$. Using this notation, the restricted equation (7) can be stated as:

$$
\bar{X}_{i} \cdot \bar{\Pi}_{i}+Z_{i}=0 .
$$

where, $Z_{i}=\beta P_{i} G\left[I_{s}-\beta P G\right]^{-1} D_{i}+X_{i}^{b} \cdot b_{i}+\bar{\varepsilon}_{i}$ and $X_{i}^{b}$ denotes a matrix of dimension $\left(K \cdot L^{N}\right) \times$ $\left((K+1)^{N-1} \cdot L\right)$ which is obtained by summing columns in the unrestricted matrix $X_{i}$ which are associated with profit values $b_{i}\left(a_{-i}, s_{i}\right)$ for $a_{i}=0$. The following Proposition states the identification result.

Proposition 4 Suppose $F$ and $\beta$ are given, and restrictions $(R 1)$ and $(R 2)$ are satisfied.

(i) If $L<K+1$, then the parameters $\left(\bar{\Pi}_{1}, \ldots, \bar{\Pi}_{N}\right)$ are not identified.

(ii) If $L \geq K+1$, and if the restricted matrix $\bar{X}_{i}$ has full column rank, then the parameter vector $\bar{\Pi}_{i}$ is identified.

The Proposition states that the identification of the profit parameters depends on the dimensionality of the state and action spaces. Part (i) says that if there are fewer states than actions, then the model is not identified. Part (ii) says that provided the number of states equals at least the number of actions, and the restricted matrix $\bar{X}_{i}$ has full column rank, then the profit parameters are identified. 
Observe that restriction (R2) in Proposition 4 is required. The intuitive reasons is that the indifference analysis determines payoffs relative to the payoff under action $a_{i}=0$ at every state only. The formal reasons is that the matrix $X_{i}$ consists of a product of matrices, $X_{i}=P_{i} \cdot\left[I_{m_{s}} \cdot m_{a}+\right.$ $\left.\beta G\left[I_{s}-\beta P G\right]^{-1} P\right]$ in which the first element in the product is the $\left(K \cdot L^{N}\right) \times\left((K+1)^{N} \cdot L\right)$ dimensional matrix $P_{i}$ given by:

$$
P_{i}=\overbrace{\left[\begin{array}{ccccc}
0 & 1 & 2 & \ldots & K \\
-P_{-i} & P_{-i} & 0 & \ldots & 0 \\
-P_{-i} & 0 & P_{-i} & \ldots & 0 \\
\vdots & 0 & 0 & \ddots & 0 \\
-P_{-i} & 0 & 0 & \ldots & P_{-i}
\end{array}\right]}^{a_{i}=}
$$

The first column in the matrix $P_{i}$, which is associated with action $a_{i}=0$, is collinear with the remaining columns in the matrix $P_{i}$ requiring that payoffs associated with one action for every state are exogenously fixed.

Part (ii) in Proposition 4 requires that the matrix $\bar{X}_{i}$ has full column rank $K \cdot(K+1)^{N-1} \cdot L$. This condition is required as the rank condition may fail. Recall our earlier example illustrating the multiplicity of equilibria. In the first two equilibria the rank of the matrix $\bar{X}_{i}$ equals 4 while in the third equilibrium the rank equals 2 only.

Next, we briefly discuss symmetric games with binary actions (and states). We describe the assumptions and the set of identifying restrictions in this case in more detail, as we will take this specification to our data.

\section{Identification in Symmetric Entry Games}

This section describes a set of identifying assumptions for symmetric entry models. We impose these assumptions in the empirical analysis.

The action space of firm $i$ is binary, $K=1$. Action 1 denotes a firm that remains active, or enters the market. Action 0 represents an exiting firm, or a firm that remains inactive.

The state space of firm $i$ consists of two elements: A binary variable $s_{i}$ that indicates whether firm $i$ was active in the preceding period, $s_{i}=2$, or inactive, $s_{i}=1$, and a demand variable $s_{0}$ $\in\left\{1, \ldots L_{d}\right\}$.

Symmetry implies that the number of other active firms is a sufficient statistic for the vector of other firms' actions $a_{-i}$. We denote the number of other active firms by $\delta$. It ranges from 0 to $N-1$. Similarly, the number of other firms with an active state is a sufficient statistic for $s_{-i}$. We 
denote the number of other firms with an active state by $\theta$. The dimensionality of the binary state space under symmetry equals $m_{s}=2 \cdot N \cdot L_{d}$. Similarly, the dimensionality of the binary action space reduces to $m_{a}=2 \cdot N$. Period profits can be written as $\pi\left(a_{i}, \delta, s_{i}, \theta, s_{0}\right)$.

Restriction $(R 1)$ can be imposed in the symmetric entry model by omitting the dependence on $\theta$ in the profit vector. To satisfy restriction $(R 2)$, we fix the exit value of an active firm at 10 , $b\left(a_{-i}, 1\right)=10$, and assume zero profits for inactive firms that are inactive in the preceding period, $b\left(a_{-i}, 0\right)=0$. We assume an annual discount factor $\beta=0.9$ and assume $F$ is the standard normal distribution function. By Proposition 4, if the associated restricted matrix $\bar{X}$ has rank $\left(2 \cdot N \cdot L_{d}\right)$, then the restricted profit vector $\bar{\Pi}$ is identified. In our application the rank condition is satisfied and the restricted profit parameters are indeed identified.

So far, we have described properties of the dynamic equilibrium and established conditions that permit identification of the parameters of the model. We illustrated the identification conditions for symmetric entry games in more detail. The next section addresses how to estimate the parameters.

\section{Estimation Approach}

This section proposes our estimator. Our estimation strategy follows the steps in the identification argument. First, we estimate the choice probabilities. Second, we infer the period profit parameters by using the linear equation (10). We characterize the properties of the estimator. We conclude the section with a discussion of the estimator for symmetric entry games and the restrictions imposed on the estimator by our data.

The potential number of firms may not be observed. By assumption, the probability that all potential firms are observed (are active) in a given period is positive and bounded away from zero. An estimator $\widehat{N}$ for the potential number of firms is then the maximum number of firms observed in any period, $\widehat{N}=\max _{t} N_{t}$. It can be verified that the estimator $\widehat{N}$ is consistent and superefficient, as it converges a rate faster than $\sqrt{T}$. The fast rate of convergence of $\widehat{N}$ implies that the asymptotic properties of the choice probabilities estimator and profit parameters estimator will not be affected by $\widehat{N}$. We can proceed as if $N$ is known.

The choices and states are multinomially distributed. This follows from the assumption that the set of feasible actions and states is finite. Let $p(k, i, s)$ denote the probability that firm $i$ selects action $k$ in state $s$. Define the observed choice frequency by $n_{k i s}=\sum_{t} \mathbf{1}_{\left\{a_{i}^{t}=k, s^{t}=s\right\}}$ for all $i \in \mathbf{N}, k \in A_{i}, s \in S$ and observed state frequency by $\left.n_{a s s^{\prime}}=\sum_{t} \mathbf{1}_{\left\{a^{t}=a, s^{t}=s, s^{t+1}=s^{\prime}\right.}\right\}$. We may write 
the log likelihood of the multinomial model as:

$$
\ell=\sum_{i \in \mathbf{N}} \sum_{k \in A_{i}} \sum_{s \in S} n_{k i s} \log p(k, i, s)+\sum_{a \in A} \sum_{s \in S} \sum_{s^{\prime} \in S} n_{a s s^{\prime}} \log g\left(a, s, s^{\prime}\right)
$$

where $\sum_{k \in A_{i}} p(k, i, s)=1$ for all $i \in \mathbf{N}, s \in S$ and $\sum_{s^{\prime} \in S} g\left(a, s, s^{\prime}\right)=1$ for all $a \in A, s \in S$. We assume that the vector of state variables at time $t=0, s^{0}$, is exogenous. An examination of the first order conditions yields that the maximum likelihood estimator equals the sample frequency:

$$
\widehat{p}(k, i, s)=\frac{n_{k i s}}{\sum_{l \in A_{i}} n_{l i s}}, \quad \widehat{g}\left(a, s, s^{\prime}\right)=\frac{n_{a s s^{\prime}}}{\sum_{s^{\prime \prime} \in S} n_{a s s^{\prime \prime}}} .
$$

Moreover, the solution to the first order condition is unique.

Let $\theta=\left(p(k, i, s), g\left(a, s, s^{\prime}\right), i \in \mathbf{N}, k \in\{1, \ldots, K\}, s \in S, a \in A, s^{\prime} \in S \backslash s_{m_{s}}\right)$ denote the parameter vector which already incorporates the restriction that probabilities sum to one. Let $D_{\theta} \ell$ denote the gradient of the log likelihood function. Let $I_{\theta}=E\left(D_{\theta} \ell\right) \cdot\left(D_{\theta} \ell\right)^{\prime}$ denote the Fischer information matrix. Billingsley (1961) establishes the asymptotic properties of maximum likelihood estimators for Markov processes, as the number of periods $T$ goes to infinity. The Markovian structure of the observed controlled process $\left(s^{t}\right)$ follows directly from the assumption that the profitability shock realizations are conditionally independently distributed, the decision rules are Markovian, and the distribution of profitability shocks is exogenous. The maximum likelihood estimator $\widehat{\theta}_{T}$ is consistent and asymptotically efficient with a normal limiting distribution given by:

$$
\sqrt{T}\left(\widehat{\theta}_{T}-\theta\right) \rightsquigarrow N\left(\mathbf{0}, I_{\theta}^{-1}\right) .
$$

Let $\Pi=\psi(\theta)$ denote the identified profit vector. We propose to estimate the profit vector by evaluating the function $\psi$ at the value of the maximum likelihood estimator of the choice and transition probabilities, $\widehat{\Pi}=\psi(\widehat{\theta})$. The properties of the estimator can be deduced by using the delta method. An examination of equation (10) reveals that $\psi$ is continuously differentiable. Let $D_{\theta} \psi$ denote the gradient of the function $\psi$. By application of the delta method, see Theorem 3.1 in Van Der Vaart (1998), the limiting distribution of $\psi(\widehat{\theta})$ is normal and given by:

$$
\sqrt{T}\left(\psi\left(\widehat{\theta}_{T}\right)-\psi(\theta)\right) \rightsquigarrow N\left(\mathbf{0},\left(D_{\theta} \psi\right) I_{\theta}^{-1}\left(D_{\theta} \psi\right)^{\prime}\right) .
$$

Moroever, Lemma 8.14 in Van Der Vaart (1998) implies that the estimator $\psi\left(\widehat{\theta}_{T}\right)$ is asymptotically efficient.

The estimator is computationally very simple. Before proceeding with the application, we discuss the restrictions that our data impose on the estimator in more detail.

\section{Estimation of Symmetric Entry Games}


We assume a deterministic state transition rule and do not estimate $g$. The assumption is satisfied if agents have perfect foresight concerning the evolution of the exogenous demand process measured by the gross domestic product. Actions are binary, $K=1$, yielding a binomial choice model.

We do not observe actions for a number of states because these states did not occur in our sample period. These data limitations lead us to adopt a parametric framework for the choice probabilities. We parameterize the choice probability in the following way:

$$
p(1, i, s)=\Phi(\alpha \cdot s)
$$

where $\Phi$ denotes the standard normal distribution and $\alpha \cdot s$ denotes a linear function of the state variables. The linear function is given by:

$$
\alpha \cdot s=\alpha_{0}+\alpha_{1} \mathbf{1}_{\left\{s_{i}^{t}=2\right\}}+\alpha_{2} \delta^{t}+\alpha_{3} \mathbf{1}_{\left\{s_{i}^{t}=2\right\}} \cdot \delta^{t}+\alpha_{4} s_{0}^{t}
$$

where $\mathbf{1}_{\left\{s_{i}^{t}=2\right\}}$ denotes an indicator function that equals one if firm $i$ is active in the preceding period and zero otherwise, $\delta^{t}=\sum_{j \neq i} \mathbf{1}_{\left\{s_{j}^{t}=2\right\}}$ denotes the Number of Other Active Firms, and $s_{0}^{t}$ denotes the log gross domestic product.

Profit Value Estimates: With the estimator $\widehat{\alpha}$ in hand, we infer $\bar{\varepsilon}$, calculate the probability matrices $P_{i}, P, G$ and the vector $D_{i}$. We assume an annual discount factor $\beta=0.9$. All the coefficients in the linear equation (10) are available and we infer the restricted period profit parameters. As explained above, the standard errors for the period profit parameters are calculated using the delta method.

The next section introduces our data for pubs, restaurants, coffeehouses, carpenters, and bakeries for two Lower Austrian cities.

\section{Data}

This section introduces our data set and gives descriptive statistics.

We have collected quarterly time series information on the identity of active pubs, restaurants, coffeehouses, carpenters and bakeries in two Austrian cities between 1982 and 2002. The data were obtained from Lower Austrian Chamber of Business. The data list all active pubs, restaurants, coffeehouses, carpenters, and bakeries in two small sized Austrian cities, Amstetten and Baden. Baden has about 24,000 inhabitants. Amstetten is of similar size with a population of about 23, 000 . We supplemented the information with quarterly gross domestic product information for Austria.

(Table I about here) 
Table I provides summary statistics. The first five columns consider Baden and the next five columns consider Amstetten. The first column in the table shows that on average there are 17.01 pubs active in Baden. The number of active pubs ranges between 12 and 22 with a standard deviation of 2.07. There is a substantial pub turnover in Baden. A total of 49 pubs were opened, while a total of 53 pubs were closed. Not adjusting for truncation at the beginning and the end of the sample period, the average active spell of a pub equals about 21.3 quarters.

Column two considers restaurants in Baden. On average a total of 13.26 restaurants are active in Baden. The number of active restaurants ranges between 6 and 25 with a standard deviation of 4.69. There is some turnover. A total of 38 restaurants were opened, while a total of 20 restaurants were closed. The average active spell of a restaurants equals about 25.32 quarters.

Column three considers coffeehouses in Baden. On average a total of 13.81 coffeehouses are active in Baden with the number of active coffeehouses ranging between 9 and 18. There is turnover. A total of 44 coffeehouses were opened, while a total of 40 coffeehouses were closed. The average active spell of a coffeehouse equals about 21.89 quarters.

Column four considers carpenters in Baden. On average a total of 11.29 carpenters are active in Baden. The number of active carpenters ranges between 9 and 15 with a standard deviation of 1.63. There is less turnover than for pubs, restaurants, or coffeehouses. A total of 16 carpenters were opened, while a total of 12 carpenters were closed. The average active spell of a carpenters equals about 37.92 quarters.

Column five considers bakeries in Baden. On average a total of 9 bakers are active in Baden ranging between 7 and 11 at any point in time. Turnover is not very pronounced with 8 bakery openings and 9 bakery closings during the sample period. The average active spell of bakery is about 44.47 quarters.

Columns six to ten report summary statistics for pubs, restaurants, coffeehouses, carpenters and bakeries in Amstetten, respectively. The average number of businesses is similar to the numbers in Baden. On average there are about 21.52 pubs, 8.33 restaurants, 14.37 coffeehouses, 13.6 carpenters and 8.88 bakeries in Amstetten. The number of newly opened businesses equals 14 and 15 for bakeries and carpenters, and 48 and 50 for pubs and coffeehouses, respectively. There are 14 closings for bakeries and carpenters and 45 and 30 closings for pubs and coffeehouses, respectively. The average active spell of a business in Amstetten ranges between 21.95 for coffeehouses and 42.30 for carpenters.

In summary, the data provide us with time series information on the identity of active pubs, restaurants, coffeehouses, carpenters and bakeries in two selected Austrian towns, Baden and Amstetten, over a time period of more than 20 years. There is persistence in the active spell of businesses. Bakeries and carpenters remain open for about ten years while pubs, coffeehouses and restaurants 
remain open for about 5 to 6 years. There is considerable turnover in these professions. In Baden a new pub is opened on average every half year, and a pub is closed at the same rate. Similarly a restaurant and coffeehouse opens every half year. For bakeries there is less turnover. In Baden a new bakery opens every 2 to 3 years and a bakery closes with the same frequency.

\section{$7 \quad$ Estimation Results}

This section reports our estimates. We begin with a description of the choice probability estimates. Then, we assess the goodness of fit of the empirical model by sampling from the distribution of choice probability estimates and comparing the resulting distribution of pseudo samples to the observed data. Finally, we describe the period profit parameter estimates.

Table II reports the maximum likelihood estimates of the probability of being active. We assume symmetric behavior and pool the decisions of all firms within a profession and city. The total number of firms ranges between 11 and 29 across professions and cities. The number is tabulated in Table I. Explanatory variables include Lagged Active which is a dummy variable that equals one if the firm was active in the preceding period, the Number of Other Active Firms equals the number of other firms that were active in the preceding period, an interaction term between Lagged Active and the Number of Other Active Firms, and Log GDP which measures the logarithm of the Austrian gross domestic product. In all specifications, we can reject the null that the coefficients are jointly insignificant.

\section{(Table II about here)}

We interpret the estimates in Table II by evaluating the probability of being active at the sample mean of Log GDP and the sample median of the Number of Other Active Firms: For all professions in both cities, Lagged Active has a significant positive effect on the decision to be active. For pubs in Baden, Lagged Active increases the probability of being active in the next period by $84 \%$. In other professions the number ranges between $83 \%$ and $94 \%$. The evidence in Amstetten is somewhat stronger. Lagged Active increases the probability of being active in the next period by $90 \%$ for pubs. In other professions the number ranges between $89 \%$ and $96 \%$.

Number of Other Active Firms has a significant effect in three professions in Baden and in all professions in Amstetten. In both cities and all professions, increasing the Number of Other Active Firms by one has a negative effect on being active. The magnitude of the effect of increasing the Number of Other Active Firms by one is small, ranging between $-0.2 \%$ and $-1.3 \%$ in Baden. In Amstetten the effect ranges between $-0.4 \%$ and $-1.1 \%$. 
Log GDP has a positive effect in two of five professions in Baden. Increasing Log GDP by 1\% increases the probability of being active by $5.8 \%$ for restaurants, by $8.2 \%$ for carpenters. For pubs, coffeehouses and bakeries the effect differs. There a 1\% increase in Log GDP lowers the probability of being active by $6.9 \%, 3.1 \%$ and $1.9 \%$, respectively. In Amstetten, Log GDP has a positive effect on being active in all professions. The Log GDP effect ranges between $0.1 \%$ and $7.6 \%$.

Higher order terms for the Number of Other Active Firms can be included in the specification of the choice probabilities. It turns out that higher order terms are not significant for most professions. We conducted likelihood ratio tests of the null hypothesis that the coefficients of second order terms for Number of Other Active Firms are equal to zero. In Baden, the null cannot be rejected at the ten percent level in four of five professions. In Amstetten, the null cannot be rejected at the ten percent level in three of five professions. The exceptions are restaurants in Baden, and pubs and coffeehouses in Amstetten.

Symmetry is imposed in the specification of Table II. With a sufficiently rich data set, asymmetry could be accounted for in the estimation. Asymmetry, which is sometimes referred to as unobserved heterogeneity in the empirical literature, can be accounted for in the estimation. For example, choice probabilities can be estimated for each firm individually by using a full set of state variables as explanatory variables. The coefficients would then account for possible asymmetric effects of opponents' state variables. Unfortunately, the number of parameters for a full asymmetric model exceeds what is feasible for the limited information available in our data. None the less, we consider a simplified specification that permits some asymmetries between firms.

The presence of unobserved heterogeneity is tested in the following way: We re-estimate the probit model by including a set of firm specific dummy variables, in addition to the variables listed in Table II. We conduct two tests: First, we test the null hypothesis of jointly not significant effects of the dummy variables. The test statistic is distributed as a chi-squared random variable. We find that at the one percent level the null of no significant effects cannot be rejected in four of five professions in Baden and in all professions in Amstetten. At the five and ten percent level, the null cannot be rejected in three of five professions in Baden and in two of five professions in Amstetten. Our second test considers the null hypothesis that the coefficients for the four explanatory variables in Table II are equal between two specifications: with and without firm dummies. The Wald test statistic is distributed as a chi-squared random variable with four degrees of freedom. We find that the null cannot be rejected for all professions in Baden and Amstetten at the ten percent level. We can conclude that asymmetries do not appear an important concern in our data.

As a measure of goodness of fit of the choice probability estimates in Table II we conduct the following experiment. We draw a random sample from the distribution of choice parameter estimates. 
We then simulate one path of the firms' choices by randomly drawing from the distribution associated with the choice parameter estimates. We repeat the exercise 100 times and compare the simulated paths to the observed path. Summary statistics for the observed path are given in Table I. Both, in Baden and Amstetten, the simulated average number of firms is somewhat lower than the observed number for all professions but the difference is small in magnitude. We cannot reject the null of no differences for all five professions in both cities. Comparing the number of entrants, exits and activity spells between the simulated and observed data reveals the following: In both, Baden and Amstetten, there are no significant differences between the observed and the simulated number of entrants, exits and activity spells in all five professions. The choice probability estimates explain turnovers accurately.

Estimates of period profit parameters in Baden and Amstetten are reported in Tables III and IV, respectively. As described above, we fix the annual discount parameter $\beta$ at 0.9 , assume that $F$ is the standard normal distribution function, assume zero profit for inactive firms that remain inactive, and fix the exit value at 10. We assume a deterministic transition rule for GDP. For out of sample future time periods, we assume that the GDP level is constant and equal to the GDP value achieved in 2002. Under these assumptions, for all five professions in both cities, the restricted matrix $\bar{X}$ appearing in equation (10) has rank $\left(2 \cdot N \cdot L_{d}\right)$. By Proposition 4 , the restricted profit vector is identified. Tables III and IV report period profit estimates of an active firm for the Number of Other Active Firms ranging from zero to $N-1$, and for two selected GDP levels. The high GDP level amounts to 12.80 in logs, achieved in the second quarter in 1992, and the low GDP level amounts to 12.53 in logs, achieved in the first quarter in 1982. Both values are at least 10 years prior to the time period where the GDP level becomes constant. Additionally, we report entry cost estimates which are defined as the profit difference between active and inactive states, $\bar{\pi}\left(1, \delta, 2, s_{0}\right)-\bar{\pi}\left(1, \delta, 1, s_{0}\right)$. We report entry cost estimates at the low GDP level only, as there is a negligibly small effect of GDP on entry costs.

(Table III about here)

The interpretation of the coefficient estimates in Table III is the following: Baden's entry cost estimates are significantly negative in all professions for all state variables. The entry cost estimates range between 11.35 and 16.06. For four of five professions the entry cost decreases monotonically with an increase in the Number of Other Active Firms suggesting that entry becomes less costly when more firms are active. The exception is bakeries. For bakeries, the entry cost increases with an increase in the Number of Other Active Firms.

Period profit estimates of a pub that was active in the preceding period in Baden are given in 
columns 2 and 4 . They range between 0.16 and 0.42 . The profit estimates are highest with few active firms and fall as the Number of Other Active Firms increases. For other professions a number of profit estimates are positive and significantly different from zero. Period profit estimates typically fall as the Number of Other Active Firms increases. An exception are coffeehouse profit estimates which increase initially and, then, decrease, as the Number of Other Active Firms increases. Bakery profit estimates are imprecisely estimated when the Number of Other Active Firms is small leading to large point estimates. The effect of GDP on period profits varies across professions. Carpenter and restaurant profit estimates increase with an increase in GDP. The profit estimates for other professions fall with an increase in GDP.

(Table IV about here)

The estimates in Amstetten are qualitatively similar to Baden. An examination of Table IV reveals that the entry cost estimates are significant negative in all professions for all state variables in Amstettten. The entry cost estimates range between 12.08 and 21.66. For all professions the entry cost decreases monotonically with an increase in the Number of Other Active Firms suggesting that entry becomes less costly when more firms are active.

Period profit estimates of a firm that was active in the preceding period in Amstetten are mostly positive. A number of profit estimates are significantly different from zero. An increase in the Number of Other Active Firms decreases period profits on most occasions in accordance with economic intuition. For restaurants, coffeehouses and carpenters the effect of an increase in the Number of Other Active Firms is positive on occasions. For instance, as the Number of Other Active Firms increases coffeehouse profit estimates evaluated at the high GDP level fall, then increase, and then fall again, while coffeehouse profit estimates evaluated at the low GDP level fall for all of the range. The effect of GDP on period profits is positive but small in magnitude on most occasions.

The profit parameter estimates in Tables III and IV illustrate substantial payoff differences between newly entered and already active firms consistent with dynamic entry models. The entry cost estimates are of much larger magnitude than the profit estimates implying that it takes a number of periods to recover the entry cost. We constructed a Chi-Squared test of the null hypothesis that the Number of Other Active Firms has no effect on profit estimates. We can reject the null of no effect in all professions and both cities. An increase in the Number of Other Active Firms decreases the profit estimates in most professions and GDP levels.

The estimates in Tables III and IV rely on two identifying assumptions. These assumptions are an annual discount factor $\beta$ fixed at 0.9 , and the exit value fixed at 10 . The effect of the identifying assumptions on the parameter estimates is readily illustrated. An increase in the discount factor $\beta$, 
decreases the profit estimates at all state variables. The entry cost estimates remain unaffected by a change in the discount factor as they are defined as the profit difference between active and inactive states, $\bar{\pi}\left(1, \delta, 2, s_{0}\right)-\bar{\pi}\left(1, \delta, 1, s_{0}\right)$. An increase in the exit value lowers the entry cost by exactly the same amount. In the extreme scenario in which the exit value is zero, most entry cost estimates in Tables III and IV remain negative and significantly different from zero. An increase in the exit value magnifies the profit estimates for active firms.

With the profit estimates at hand, we can numerically calculate equilibria by using equation (8). From section 3 we know that the numerical calculation need not yield the equilibrium outcome that is observed because the model can exhibit multiple equilibria. However, in our case, repeated numerical calculations yield choice probabilities almost identical to the choice probability estimates in Table II. A possible reason is that the zeros of equation (8) are locally unique. With starting values that are not too far away from the choice probability estimates in Table II, numerical algorithms tend to converge to the same solution.

In sum, the estimates of choice probabilities fit the time series data for pubs, restaurants, coffeehouses, carpenters and bakeries in Baden and Amstetten well. Our goodness of fit test indicates that the model explains the data accurately. The profit parameter estimates confirm substantial payoff differences between newly entered and already active firms consistent with dynamic entry models. Additionally, we can reject the null that the Number of Other Active Firms has no effect in all professions confirming the importance of strategic effects. The effect of the Number of Other Active Firms on period profit estimates has the expected sign in most professions. With all the profit estimates at hand, we can illustrate firms' decisions and assess policy questions. This is done in the next section.

\section{Value Function Estimates and Entry Tax}

This section considers two applications of our estimates. Subsection 8.1. depicts the long run expected discounted sum of payoffs to active and inactive firms. Subsection 8.2. conducts the policy experiments in which the regulator imposes a unit tax on firms wishing to enter.

\subsection{Value Function Estimates}

This section illustrates our estimates for the discounted sum of firms' payoffs for carpenters in Baden. We select carpenters in Baden to illustrate interesting payoff differences between active and inactive firms. Additionally, we illustrate differences between short and long run payoffs. Estimates for other 
professions yield qualitatively similar results. The discounted sum of payoffs is calculated from the period profit estimates by using the formula given in equation (3) in section 2 .

(Figures 1 - 4 about here)

Figures 1 to 4 depict the ex ante value function estimates as a function of the Number of Other Active Firms. The ex ante value function is defined as the expected discounted sum of payoffs before the profitability shock is observed and before the action is taken. The ex ante value function is plotted as a solid line. The remaining state variables, active or inactive and the GDP level, are fixed at four distinct values. These values include inactive firms at a high GDP level, active firms at a high GDP level, inactive firms at a low GDP level, and active firms at a low GDP level. The dotted lines in Figures 1 to 4 depict $90 \%$ confidence intervals.

Figure 1 shows that the ex ante value function of an inactive firm at the high GDP level ranges between 1.74 and 1.95, and does not change significantly as the Number of Other Active Firms increases. Figure 2 shows that the ex ante value of an active firm at the high GDP level is substantially higher than that of an inactive firm. It ranges between 13.19 and 16.79. The level difference is attributable to the entry cost. The ex ante value function of an active firm declines significantly as the Number of Other Active Firms increases. The reason is that an additional firm lowers the expected period payoff to an active firm. In total, the ex ante value function declines by about $27 \%$ as the Number of Other Active Firms increases from 0 to 14.

The value function estimates at the low GDP level, which are depicted in Figures 3 and 4, are qualitatively similar to those in Figures 1 and 2. The effect of a reduction in the GDP level is to decrease the value function estimates. The value function of an inactive firm is again almost constant in the Number of Other Active Firms at about 1.0, while the value function of an active firm falls with an increase in the Number of Other Active Firms. It falls from 15.40 to 11.93. The ex ante value function estimate declines by about $29 \%$ as the Number of Other Active Firms increases from 0 to 14 .

Comparing the long run value function estimates with the short run profit estimates in Table III reveals that GDP and the Number of Other Active Firms have a stronger effect in the short run than in the long run.

\subsection{Entry Tax}

This section reports a policy experiment of a tax on entry. We select carpenters in Baden and assess the effect of the tax on the equilibrium outcome. 
The experiment is as follows: We draw a random sample from the distribution of profit estimates for carpenters described in Table III. We increase the entry cost estimate by one unit at all state variables. We then numerically calculate the new equilibrium based on the modified period payoffs by using equation (8). The equilibrium choice probabilities are then used to simulate one path of firms' choices by randomly drawing from the distribution associated with the equilibrium choice parameters. We repeat the exercise 60 times and compare the simulated after tax equilibrium paths to the observed path. Summary statistics for the observed path are given in Table I.

Somewhat surprisingly, the tax does not affect the distribution of the number of active firms significantly. The after tax simulated average number of active firms equals 11.14 with a standard deviation of 0.64 . The number is not significantly different from the mean number of active firms in Table I which equals 11.29. The minimum and maximum number of active firms on average across simulations equal 13.7 and 8.83 , respectively, which are again not significantly different from the before tax counterpart in Table I.

The tax alters the number of turnovers. Turnovers become less frequent. The number of entrants falls by more than $50 \%$, from 16 to 6.93 on average across simulations. The number of exiting firms falls by about $80 \%$, from 12 to 2.6 on average. The reduction in the number of turnovers is significant with standard deviations across simulations of 2.02 and 1.83 for the number of entrants and exiting firms, respectively. The duration of the mean active spell increases by about $60 \%$ to 59.44 . The increase in the mean active spell is significant.

The reduction in turnovers as a result of the tax can be explained by using the indifferent type analysis described in section 3. The range of profitability shocks in which an inactive firm decides to enter is reduced as a larger profitability shock is required to offset the increased entry cost. On the other hand, the range of profitability shocks in which an active firm decides to remain active is increased as the continuation value when exiting is reduced due to the tax. Hence, the ex ante expected profitability shock when active is reduced.

An examination of the average value functions across simulations reveals the following: The expected discounted sum of payoffs for an inactive firm is substantially reduced due to the tax. The reduction is significant. The value function of an inactive firm, evaluated at the high or low GDP level which is depicted in Figures 1 and 3, falls by $56 \%$ to $63 \%$ across the range of the Number of Other Active Firms. The decrease in value ranges between 1.05 and 1.10 in absolute value at the high GDP level and between 0.57 and 0.59 in absolute value at the low GDP level.

For most of the range of state variables, active firms take a small percentage fall in expected discounted sum of payoffs. The change ranges between $-7 \%$ and $+2 \%$ across the range of all state variables, but is not significant at any point. The change in absolute value at the high GDP level 
ranges between -0.21 and -0.97 . The change in absolute value at the low GDP level ranges between -0.48 and +0.25 .

We calculate the tax effect on all firms as the difference in the sum of pre and post value functions of all firms combined. The net tax effect on firms is negative. The total loss ranges between -2.92 and -8.77 across the range of the number of active firms. Some of the firms' losses will be offset by the revenues generated by the tax. We find that the expected sum of discounted tax revenues ranges between +2.37 and +7.55 over the range of the number of active firms. Adding the net tax effect on firms and the tax revenues implies a total tax effect ranging between -4.78 and +0.45 over the range of the number of firms. As the number of active firms increases, the total effect increases initially, peaking between 6 and 7 firms, and then decreases. The total tax effect is not significantly different from zero for any number of firms.

Increasing the tax to three units yields results qualitatively similar to the unit tax case: The distribution of the number of active firms remains not significantly different from the before tax distribution. The number of turnovers and the expected discounted sum of payoffs for an inactive firm are reduced due to the tax and more so than with a unit tax. The average value function of an active firm becomes steeper with the three-unit tax. It is higher with a small Number of Other Active Firms and lower with a large Number of Other Active Firms relative to the before tax value function. The difference is marginally significant at some values of the Number of Other Active Firms. The total tax effect, calculated as the sum of the net tax effect on firms plus the tax revenues, is not significantly different from zero for most of the range of the number of firms. It is marginally significant positive with seven to nine firms and marginally significant negative with 15 firms.

In sum, the tax does not affect the long-run number of active firms. Instead, it reduces the frequency of turnovers as it makes entry more costly. The tax adversely affects inactive firms as the cost of entry is increased. Already active firms are not significantly affected by the tax for most of the range of the number of firms. Taking the tax revenues into account, the total effect on the sum of future discounted payoffs is on occasions positive but not significant for most of the range of the number of firms.

\section{Conclusion}

This paper proposes a new estimation method for Markovian games with finite actions. The basis of our analysis is a necessary and sufficient equilibrium condition for dynamic games. The equilibrium condition permits us to characterize the identification conditions of the underlying model parameters. 
We propose an estimation method following the steps in the identification argument. The estimator is efficient and computationally easy to implement. We apply the proposed estimator to time series data on entry and exit decisions for a number of professions in two Austrian cities. The model fits the data well. Dynamic effects are important as active firms are very likely to remain active in the next period. We calculate the effect of an entry tax on the equilibrium outcome. Somewhat surprisingly, the distribution of active firms does not change significantly as a result of the tax but the number of turnovers is reduced significantly. While the characterization of the identification conditions is reasonably complete, the estimator is computationally simple, and policy experiments can be conducted, there are at least two shortcomings in our analysis:

First, not all the primitives of the model are identifiable as the discount factor and the distribution of unobserved profitability shocks are not identified. It may be possible to alleviate the non-identification concern by adopting a formulation that omits the profitability shock. In the absence of a profitability shock, firms will not necessarily adopt pure strategies. Instead, firms may randomize between alternative actions. The resulting mixed strategy equilibrium will generate endogenously a distribution over different outcomes which may form the basis for an alternative estimation approach.

Second, the assumption of Markovian strategies is restrictive as it does not permit full history dependent behavior. An increase in the state space would permit strategies to be richer functions of past actions. However, full history dependent behavior, which plays a prominent role in the development of the theory of strategic dynamic games, cannot be captured.

\section{Appendix}

Proof of Proposition 1. Consider a typical firm $i$ deciding between action $k$ and action 0 at any state $s$. By assumption, the payoff function is linear in the private profitability shock $\varepsilon^{k}$. If there exists a point $\bar{\varepsilon}^{k}$ such that a firm of type $\bar{\varepsilon}^{k}$ is indifferent between actions $k$ and 0 , then any type with a smaller profitability shock, $\varepsilon^{k}<\bar{\varepsilon}^{k}$, will prefer action 0 to action $k$. On the other hand, any type with a higher profitability shock, $\varepsilon^{k}>\bar{\varepsilon}^{k}$, will prefer action $k$ to action 0 . The reason is that the profitability shock $\varepsilon^{k}$ affects the current period payoff under action $k$ only. Future payoffs and current period payoffs under action $k^{\prime} \neq k$ are unaffected by $\varepsilon^{k}$.

Next, consider a type $\left(\varepsilon^{k}, \varepsilon^{k^{\prime}}\right)$ for any $k, k^{\prime} \neq 0$. By transitivity, if the type is indifferent between actions $k$ and 0 , and indifferent between actions 0 and $k^{\prime}$, then the type is also indifferent between action $k$ and $k^{\prime}$. Furthermore, transitivity implies that if $\varepsilon^{k}-\bar{\varepsilon}^{k}>\varepsilon^{k^{\prime}}-\bar{\varepsilon}^{k^{\prime}}$, then type $\left(\varepsilon^{k}, \varepsilon^{k^{\prime}}\right)$ prefers action $k$ to actions $k^{\prime}$ and 0 , while if $\varepsilon^{k}-\bar{\varepsilon}^{k}<\varepsilon^{k^{\prime}}-\bar{\varepsilon}^{k^{\prime}}$, then type $\left(\varepsilon^{k}, \varepsilon^{k^{\prime}}\right)$ prefers action $k^{\prime}$ 
to actions $k$ and 0 .

Finally, we need to show that the indifferent points $\bar{\varepsilon}=\left(\bar{\varepsilon}^{1}, \ldots, \bar{\varepsilon}^{K}\right)$ exist. The indifferent $\bar{\varepsilon}^{k}$ type receives the same expected discounted sum of payoffs under action $k$ as under action 0 , which leads to the indifference equation:

$$
\begin{aligned}
& \sum_{a_{-i} \in A_{-i}} \operatorname{Pr}\left(a_{-i} \mid s\right) \cdot\left[\pi_{i}\left(a_{-i}, k, s\right)+\beta \sum_{s^{\prime} \in S} g\left(a_{-i}, k, s, s^{\prime}\right) V_{i}\left(s^{\prime}\right)\right]+\bar{\varepsilon}^{k} \\
= & \sum_{a_{-i} \in A_{-i}} \operatorname{Pr}\left(a_{-i} \mid s\right) \cdot\left[\pi_{i}\left(a_{-i}, 0, s\right)+\beta \sum_{s^{\prime} \in S} g\left(a_{-i}, k, s, s^{\prime}\right) V_{i}\left(s^{\prime}\right)\right]
\end{aligned}
$$

By assumption, the period return $\Pi_{i}$ and the ex ante expected profitability shock are bounded. The discount factor $\beta$ is less than 1 and, hence, the value function is bounded. In turn this implies that the first expression on the left hand side and the expression on the right hand side in equation (12) are bounded. Hence, the indifferent point $\bar{\varepsilon}^{k}$, which equals the difference between those two expressions, is contained in a bounded interval, and there exists a finite positive number $E$ such that $\bar{\varepsilon}^{k} \in[-E, E]$. Hence, the indifferent points $\bar{\varepsilon}=\left(\bar{\varepsilon}^{1}, \ldots, \bar{\varepsilon}^{K}\right)$ must exist, since, by assumption, the support of $\varepsilon^{k}$ is unbounded. This establishes the result.

Proof of Proposition 2. First, we show that equation (7) must be satisfied in any equilibrium. It is an immediate consequence from Proposition 1, that for every $i$ the indifferent $\bar{\varepsilon}_{i}^{k}$ type receives the same expected discounted sum of payoffs under action $k$ as under action 0 , which leads to the indifference equation:

$$
\begin{aligned}
& \sum_{a_{-i} \in A_{-i}} \operatorname{Pr}\left(a_{-i} \mid s\right) \cdot\left[\pi_{i}\left(a_{-i}, k, s\right)+\beta \sum_{s^{\prime} \in S} g\left(a_{-i}, k, s, s^{\prime}\right) V_{i}\left(s^{\prime}\right)\right]+\bar{\varepsilon}_{i}^{k}(s) \\
= & \sum_{a_{-i} \in A_{-i}} \operatorname{Pr}\left(a_{-i} \mid s\right) \cdot\left[\pi_{i}\left(a_{-i}, 0, s\right)+\beta \sum_{s^{\prime} \in S} g\left(a_{-i}, k, s, s^{\prime}\right) V_{i}\left(s^{\prime}\right)\right]
\end{aligned}
$$

Equation (13) is a necessary equilibrium condition that must be satisfied at every state $s \in S$ and for every action $k=1, \ldots, K$ yielding a total of $m_{s} \cdot K$ equations with $m_{s} \cdot k$ indifferent types, one for each possible state and action. We may compactly write equation (13) in matrix form. Let $\bar{\varepsilon}_{i}=\left[\bar{\varepsilon}_{i}(s)\right]_{s \in S}$ be the $\left(m_{s} \cdot K\right) \times 1$ dimensional vector of indifferent types; let $P_{-i}$ be the $m_{s} \times m_{s} \cdot(K+1)^{N-1}$ dimensional matrix consisting of choice probability $\operatorname{Pr}\left(a_{-i} \mid s\right)$ in row $s$ column $\left(a_{-i}, s\right)$, and zero entries in row $s$ column $\left(a_{-i}, s^{\prime}\right)$ with $s^{\prime} \neq s$; and define the $\left(m_{s} \cdot K\right) \times\left(m_{a} \cdot m_{s}\right)$ 
dimensional matrix $P_{i}(\bar{\varepsilon})$ as:

$$
P_{i}(\bar{\varepsilon})=\overbrace{\left[\begin{array}{ccccc}
-P_{-i} & P_{-i} & 0 & \ldots & 0 \\
-P_{-i} & 0 & P_{-i} & \ldots & 0 \\
\vdots & 0 & 0 & \ddots & 0 \\
-P_{-i} & 0 & 0 & \ldots & P_{-i}
\end{array}\right]}^{a_{i}}
$$

We can re-state equation (13) as:

$$
P_{i}(\bar{\varepsilon}) \Pi_{i}+\beta P_{i}(\bar{\varepsilon}) G V_{i}+\bar{\varepsilon}_{i}=0
$$

Next, we substitute equation (3) into equation (14) to obtain an equation that characterizes the equilibrium indifference points $\bar{\varepsilon}_{i}$. To do so, notice that the vector of ex ante expected profitability shocks can be restated using the indifference points:

$$
D_{i}(s)=\left[\sum_{k=1}^{K} \int_{\bar{\varepsilon}_{i}^{k}(s)}^{\infty} \varepsilon^{k} \prod_{k^{\prime} \geq 1, k^{\prime} \neq k} F\left(\varepsilon^{k}+\bar{\varepsilon}^{k^{\prime}}-\bar{\varepsilon}^{k}\right) f\left(\varepsilon^{k}\right) d \varepsilon^{k}\right]_{s \in S}
$$

which leads us to the characterization stated in the Proposition. This establishes the first part.

Next, we take for every firm $i$ a vector $\bar{\varepsilon}_{i}$ that satisfies equation (7). We need to construct a Markovian strategy, beliefs and a continuation value and show that they constitute an equilibrium. For a given $\bar{\varepsilon}_{i}$, we define the Markovian strategy as in Proposition 1, as:

$$
a_{i}\left(\varepsilon_{i}, s\right)=\left\{\begin{array}{cc}
k & \text { if } \varepsilon_{i}^{k}>\bar{\varepsilon}_{i}^{k}(s) \text { and for all } k^{\prime} \neq k: \varepsilon_{i}^{k}-\varepsilon^{k^{\prime}}>\bar{\varepsilon}_{i}^{k}(s)-\bar{\varepsilon}_{i}^{k^{\prime}}(s) \\
0 & \text { if } \varepsilon_{i}^{k}<\bar{\varepsilon}_{i}^{k}(s) \text { for all } k .
\end{array}\right.
$$

The above decision rule yields beliefs which we denote with the choice probability matrix $P(\bar{\varepsilon})$. The decision rule also implies expected profitability shocks which we denote as $D_{i}(\bar{\varepsilon})$. As in equation (3), the value function is then given by:

$$
V_{i}=\left[I_{s}-\beta P(\bar{\varepsilon}) G\right]^{-1}\left[P(\bar{\varepsilon}) \Pi_{i}+D_{i}(\bar{\varepsilon})\right]
$$

By construction, the decision rule is optimal for the above continuation value and beliefs. Further, the beliefs are consistent. This establishes the desired result.

Proof of Theorem 1. We need to show that equation (7) has a solution. We can re-write the equation to define the function $h=\left(h_{1}, \ldots, h_{N}\right)$ with component $h_{i}$ given by:

$$
\begin{aligned}
\bar{\varepsilon}_{i} & =h_{i}(\bar{\varepsilon}) \\
& =-P_{i}(\bar{\varepsilon}) \Pi_{i}-\beta P_{i}(\bar{\varepsilon}) G\left[I_{s}-\beta P(\bar{\varepsilon}) G\right]^{-1}\left[P(\bar{\varepsilon}) \Pi_{i}+D_{i}(\bar{\varepsilon})\right]
\end{aligned}
$$


A fixed point of the function $h$ will be a zero of equation (7). By assumption, the expected period payoff is bounded and, hence, the ex ante value function is bounded. As is shown in the proof of Proposition 1, we can deduce that the set of indifference points $\bar{\varepsilon}_{i}$ is contained in some bounded interval $[-E, E]^{m_{s} \cdot K}$ for some $E$. In turn, this implies that $h$ has domain and range $[-E, E]^{m_{s} \cdot K \cdot N}$. The elements entering the function $h$ are continuous, as the decision rule, characterized in Proposition 1, and the resulting choice probability matrix are continuous in $\bar{\varepsilon}$. Brouwer's fixed point theorem implies that there exists a fixed point $\bar{\varepsilon}$ of the function $h$. By Proposition 2, the fixed point corresponds to an equilibrium.

Proof of Corollary 1. The arguments in the proofs of Proposition 1, Proposition 2 and Theorem 1 do not rely on asymmetry. The same arguments remain valid with the symmetry assumption in place.

Proof of Lemma 1. Pick any state $s \in S$ and firm $i \in N$. Denote with $\phi^{k}(\bar{\varepsilon})$ the probability that action $k$ is chosen. Elementary calculus shows that the probability equals:

$$
\begin{aligned}
\phi^{k}(\bar{\varepsilon}) & =\operatorname{Pr}\left(\varepsilon_{i}^{k}>\bar{\varepsilon}^{k} \text { and for all } k^{\prime} \neq k: \varepsilon_{i}^{k}-\varepsilon_{i}^{k^{\prime}}>\bar{\varepsilon}^{k}-\bar{\varepsilon}^{k^{\prime}}\right) \\
& =\int_{\bar{\varepsilon}^{k}}^{\infty} \prod_{k^{\prime} \geq 1, k^{\prime} \neq k} F\left(\varepsilon^{k}+\bar{\varepsilon}^{k^{\prime}}-\bar{\varepsilon}^{k}\right) f\left(\varepsilon^{k}\right) d \varepsilon^{k}
\end{aligned}
$$

Let $\phi^{0}(\bar{\varepsilon})=1-\sum_{l=1}^{K} \phi^{l}(\bar{\varepsilon})$ denote the probability of action 0. It equals $\prod_{k^{\prime} \geq 1} F\left(\bar{\varepsilon}^{k}\right)$. Let $P^{k}$ denote the observed probability that firm $i$ selects action $k$, and define the function $\psi: \Re^{K} \rightarrow \Re^{K}$ where $\psi(\bar{\varepsilon})=\left(\phi^{1}(\bar{\varepsilon})-P^{1}, \ldots, \phi^{K}(\bar{\varepsilon})-P^{K}\right)$. A zero of the function $\psi$ corresponds to a solution in equation (9). By assumption, the function $F$ is differentiable and, hence, $\phi$ is differentiable. Taking the derivative shows that $\phi$ satisfies the gross substitute property: $\frac{\partial \phi^{k}}{\partial \bar{\varepsilon}^{k}}<0$ and $\frac{\partial \phi^{k}}{\partial \bar{\varepsilon}^{k}}>0$ for $k^{\prime} \neq k$. Let $D \psi$ denote the gradient of $\psi$. Since, by construction, $\sum_{l=0}^{K} \phi^{l}(\bar{\varepsilon})=1$, and $\frac{\partial \phi^{0}}{\partial \bar{\varepsilon}^{k}}>0$, it follows that $D \psi$ has a negative and dominant diagonal, $-\frac{\partial \phi^{k}}{\partial \bar{\varepsilon}^{k}}>\sum_{k^{\prime}=1, k^{\prime} \neq k}^{K} \frac{\partial \phi^{k}}{\partial \bar{\varepsilon}^{k}}$. Hence, $D \psi$ is non-singular.

We show that there exists a $\underline{\varepsilon}$ such that $\psi^{l}(\underline{\varepsilon})<0$ for all $l \geq 1$. By assumption the probability $P^{k}$ is bounded away from zero, $P^{k} \geq \delta>0$ for all $k$. Pick $\underline{\varepsilon}^{1}=F^{-1}(1-\delta)+1$. Consider the following inequalities:

$$
\begin{aligned}
\phi^{l}\left(\underline{\varepsilon}^{1}, \ldots, \underline{\varepsilon}^{1}\right) & =\int_{\underline{\varepsilon}^{1}}^{\infty} F\left(\varepsilon^{k}\right)^{K-1} f\left(\varepsilon^{k}\right) d \varepsilon^{k} \\
& \leq \int_{\underline{\varepsilon}^{1}}^{\infty} f\left(\varepsilon^{k}\right) d \varepsilon^{k} \\
& <\delta .
\end{aligned}
$$

The first inequality uses that $F\left(\varepsilon^{k}\right)^{K-1} \leq 1$. The second inequality uses that by construction, $F\left(\underline{\varepsilon}^{1}-1\right)=1-\delta$ and, thus, $\int_{\underline{\varepsilon}^{1}}^{\infty} f(\varepsilon) d \varepsilon<\delta$. Since $P^{l} \geq \delta$, it follows that $\psi^{l}\left(\underline{\varepsilon}^{1}, \ldots, \underline{\varepsilon}^{1}\right)<0$ for all 
$l \geq 1$

Next, we show that there exists a $\bar{\varepsilon}$ such that $\psi^{l}(\bar{\varepsilon})>0$ for all $l \geq 1$. Clearly, there exists a $\varepsilon$ such that $\sum_{l=1}^{K} \psi^{l}(\varepsilon)>0$. To see this, fix $\bar{\varepsilon}^{k}=\varepsilon^{1}$ for all $k^{\prime} \geq 1$ and observe that by construction:

$$
\begin{aligned}
\sum_{l=1}^{K} \psi^{l}\left(\varepsilon^{1}, \ldots, \varepsilon^{1}\right) & =1-\phi^{0}\left(\varepsilon^{1}, \ldots, \varepsilon^{1}\right)-\sum_{l=1}^{K} P^{l} \\
& =1-F\left(\varepsilon^{1}\right)^{K}-\sum_{l=1}^{K} P^{l} .
\end{aligned}
$$

Since $\sum_{l=1}^{K} P^{l}=1-P^{0}$ with $P^{0}$ bounded away from zero, we can pick $\varepsilon^{1}$ sufficiently low, and have $\sum_{l=1}^{K} \psi^{l}(\varepsilon)>0$. Now, by the implicit function theorem and the gross substitute property, we can increase $\varepsilon^{k^{\prime}}$ for $k^{\prime}$ with $\psi^{k^{\prime}}(\varepsilon)>0$ while holding $\sum_{l=1}^{K} \psi^{l}(\varepsilon)$ constant. Since, eventually, $\psi^{k^{\prime}}(\varepsilon)$ approaches zero, there must exist a $\varepsilon$ such that $\psi^{l}(\varepsilon)>0$ for all $l \geq 1$.

Since there exist $\bar{\varepsilon}, \underline{\varepsilon}$ such that $\psi^{l}(\bar{\varepsilon})>0, \psi^{l}(\underline{\varepsilon})<0$ for all $l \geq 1$, by continuity of $\psi$ there exists a $\bar{\varepsilon}$ such that $\psi^{l}(\bar{\varepsilon})=0$ for all $l \geq 1$.

It remains to show that the zero is unique. Suppose there are two zeros. That is there are $\bar{\varepsilon}, \bar{\varepsilon}^{\prime}$ with the property $\psi^{l}(\bar{\varepsilon})=0, \psi^{l}\left(\bar{\varepsilon}^{\prime}\right)=0$ for all $l \geq 1$. By the mean value theorem there exists a point $\bar{\varepsilon}^{\prime \prime}$ such that $\left.\frac{\partial \psi^{l}(\bar{\varepsilon})}{\partial \bar{\varepsilon}^{k}}\right|_{\bar{\varepsilon}=\bar{\varepsilon}^{\prime \prime}}=0$ for all $l \geq 1$. The gradient $D \psi$ evaluated at $\bar{\varepsilon}^{\prime \prime}$ must be singular, contradicting the non-singularity of $D \psi$. Hence, the zero is unique.

Proof of Proposition 3. Part (iii): Pick any strict monotone and continuous distribution function $F$ defined on $\Re$ and pick any $\beta$. By Lemma 1 , there is a unique $\bar{\varepsilon}(F)$ and $D(F)$. For any firm $i$, condition (7) consists of $K \cdot L^{N}$ equations of the form $A_{j} \Pi_{i}+B_{j}=0$ in which the numbers in $A_{j}$ and $B_{j}$ are given. The unknown parameter vector $\Pi_{i}$ has a total of $(K+1)^{N} \cdot L^{N}$ parameters. Clearly, the number of parameters exceeds the number of equations, and elementary properties of linear equations establish that the parameter vector $\Pi_{i}$ is not identified.

Parts (i) and (ii) follow immediately from part (iii).

Proof of Proposition 4. By definition, the matrix $X_{i}$ is of dimension $\left(K \cdot L^{N}\right) \times\left((K+1)^{N}\right.$. $\left.L^{N}\right)$, and the profit vector $\Pi_{i}$ of dimension $\left((K+1)^{N} \cdot L^{N}\right) \times 1$. Restriction $(R 1)$ fixes $(K+1)^{N}$. $\left(L^{N}-L\right)$ profit parameters, leaving a total of $(K+1)^{N} \cdot L$ profit parameters unknown. Restriction $(R 2)$ fixes additionally $(K+1)^{N-1} \cdot L$ profit parameters. Imposing restrictions $(R 1)$ and $(R 2)$ together yields the restricted matrix $\bar{X}_{i}$ of dimension $\left(K \cdot L^{N}\right) \times\left(K \cdot(K+1)^{N-1} \cdot L\right)$. It is obtained by summing columns in the unrestricted matrix $X_{i}$ which are associated with identical profit values. The restricted profit parameter vector $\bar{\Pi}_{i}$ has dimension $\left(K \cdot(K+1)^{N-1} \cdot L\right) \times 1$.

By elementary properties of linear equations, the parameter vector $\bar{\Pi}_{i}$ is identified provided the matrix $\bar{X}_{i}$ has full column rank. Full column rank is achieved if the rank equals $K \cdot(K+1)^{N-1}$. $L$. Now, the number of rows in $\bar{X}_{i}$ equals $K \cdot L^{N}$, while the number of columns in $\bar{X}_{i}$ equals 
$K \cdot(K+1)^{N-1} \cdot L$. Clearly, if $L \geq K+1$, then the matrix $\bar{X}_{i}$ can have full column rank. This establishes part (ii) in the Proposition. On the other hand, if $L<K+1$, then the rank of the matrix

$\bar{X}_{i}$ is strictly less than $K \cdot(K+1)^{N-1} \cdot L$. Hence, the matrix $\bar{X}_{i}$ does not have full column rank. This establishes part (i) in the Proposition.

\section{References}

[1] Aguirregabiria, V. and Mira P. (2002), Sequential Simulated-Based Estimation of Dynamic Discrete Games, technical report, Boston University.

[2] Berry, S. (1992), Estimation of a Model of Entry in the Airline Industry, Econometrica, 60, 889-917.

[3] Billingsley, P. (1968), Convergence of Probability Measures, John Wiley, New York.

[4] Bresnahan, T.F. and Reiss P.C. (1987), Do Entry Conditions vary across markets, Brookings Papers in Economic Activities: Microeconomic Annual, 1, 833-882.

[5] Bresnahan, T.F. and Reiss P.C. (1990), Entry in Monopoly Markets, Review of Economic Studies, $57,531-544$.

[6] Bresnahan, T.F. and Reiss P.C. (1991), Entry and Competition in Concentrated Markets, Journal of Political Economy, 99(5), 977-1009.

[7] Davis, P. (1999), Spatial Competition in Retail Markets: Motion Theaters, technical report, MIT.

[8] Hotz, J. and Miller R.A. (1993), Conditional Choice Probabilities and the Estimation of Dynamic Models, Review of Economic Studies, 60, 497-529.

[9] Jofre-Bonet M. and Pesendorfer M. (2000), Bidding Behavior in a Repeated Procurement Auction: A Summary, European Economic Review, 44, 1006-1020.

[10] Jofre-Bonet M. and Pesendorfer M. (2002), Estimation of a Dynamic Auction Game, forthcoming in Econometrica.

[11] Magnac T. and Thesmar D. (2002), Identifying Dynamic Discrete Decision Processes, Econometrica, 70, 801-816.

[12] Maskin, E. and Tirole, J. (1994), Markov Perfect Equilibrium, technical report, Harvard University. 
[13] Maskin, E. and Tirole, J. (2001), Markov Perfect Equilibrium I: Observable Actions, Journal of Economic Theory, 100, 191-219.

[14] Mazzeo, J.M. (2002), Product Choice and Oligopoly Market Structure, RAND Journal of Economics, 33, 221-242.

[15] Pakes, A. and Berry S. (2002), Two Estimators for the Parameters of Discrete Dynamic Games (with Entry/Exit Examples), technical report, Harvard University.

[16] Pakes, A. and P. McGuire (2001), Stochastic Algorithms, Symmetric Markov Perfect Equilibrium, and the 'Curse' of Dimensionality, Econometrica, 69, 1261-1282.

[17] Rust. J. (1994), Structural Estimation of Markov Decision Processes, in Handbook of Econometrics, Vol 4, Engle, R.F. and McFadden D.L. eds, Elsevier, North-Holland, 3081-3143.

[18] Seim, K. (2002), Spatial Differentiation and Market Structure: The Video Retail Industry, PhD Dissertation, Yale University.

[19] Tamer, E (2003), Empirical Strategies for Estimating Discrete Games with Multiple Equilibria, Review of Economic Studies, 70.

[20] Van Der Vaart, A.W. (1998), Asymptotic Statistics, Cambridge University Press, Cambridge, U.K. 
Table I: Descriptive Statistics ${ }^{*}$

\begin{tabular}{|c|c|c|c|c|c|}
\hline & \multicolumn{5}{|c|}{ Baden } \\
\hline & Pub & Restaurant & Coffeehouse & Carpenter & Bakery \\
\hline \multicolumn{6}{|l|}{ No of Firms } \\
\hline \multirow[t]{2}{*}{ Mean } & 17.01 & 13.26 & 13.81 & 11.29 & 9 \\
\hline & (2.07) & (4.69) & $(1.65)$ & $(1.63)$ & $(0.93)$ \\
\hline Minimum & 12 & 6 & 9 & 9 & 7 \\
\hline Maximum & 22 & 25 & 18 & 15 & 11 \\
\hline No of Entrants & 49 & 38 & 44 & 16 & 8 \\
\hline No of Exiting Firms & 53 & 20 & 40 & 12 & 9 \\
\hline \multirow[t]{4}{*}{ Mean Active Spell } & 21.33 & 25.32 & 21.89 & 37.92 & 44.47 \\
\hline & (21.23) & (24.52) & (20.59) & (30.38) & $(28.92)$ \\
\hline & \multicolumn{5}{|c|}{ Amstetten } \\
\hline & Pub & Restaurant & Coffeehouse & Carpenter & Bakery \\
\hline \multicolumn{6}{|l|}{ No of Firms } \\
\hline \multirow[t]{2}{*}{ Mean } & 21.52 & 8.33 & 14.37 & 13.60 & 8.88 \\
\hline & $(2.56)$ & $(2.12)$ & $(6.84)$ & $(1.21)$ & (1.52) \\
\hline Minimum & 17 & 4 & 5 & 12 & 7 \\
\hline Maximum & 29 & 12 & 28 & 17 & 14 \\
\hline No of Entrants & 48 & 23 & 50 & 15 & 14 \\
\hline No of Exiting Firms & 45 & 16 & 30 & 14 & 14 \\
\hline \multirow[t]{2}{*}{ Mean Active Spell } & 26.99 & 25.93 & 21.95 & 42.30 & 32.43 \\
\hline & (24.24) & (26.14) & (22.27) & $(27.74)$ & (27.31) \\
\hline
\end{tabular}

* Standard deviations are displayed in parenthesis. 
Table II: Probit Estimates of the Decision to be Active

\begin{tabular}{|c|c|c|c|c|c|}
\hline & \multicolumn{5}{|c|}{ Baden } \\
\hline & Pub & Restaurant & Coffeehouse & Carpenter & Bakery \\
\hline Log Likelihood & -372.73 & -250.81 & -302.70 & -123.02 & -79.11 \\
\hline No of Observations & 1826 & 2075 & 1494 & 1245 & 913 \\
\hline \multirow[t]{2}{*}{ Constant } & 9.61 & -18.05 & 3.54 & -26.85 & 9.40 \\
\hline & (5.68) & $(14.03)$ & (4.81) & (12.73) & $(11.23)$ \\
\hline \multirow{2}{*}{ Lagged Active } & 4.40 & 4.79 & 4.78 & 6.08 & 2.18 \\
\hline & $(0.88)$ & $(0.39)$ & $(0.96)$ & $(1.21)$ & $(2.33)$ \\
\hline \multirow[t]{2}{*}{ Number of Other Active Firms } & 0.03 & 0.04 & 0.05 & -0.03 & -0.31 \\
\hline & $(0.05)$ & (0.04) & $(0.06)$ & $(0.12)$ & $(0.23)$ \\
\hline \multirow[t]{2}{*}{ (Lagged Active)*(No of Other Active Firms) } & -0.09 & -0.08 & -0.14 & -0.22 & 0.20 \\
\hline & $(0.05)$ & $(0.03)$ & $(0.07)$ & $(0.11)$ & $(0.28)$ \\
\hline \multirow[t]{4}{*}{ Log GDP } & -0.87 & 1.23 & -0.42 & 1.99 & -0.66 \\
\hline & $(0.42)$ & $(1.13)$ & $(0.38)$ & $(1.06)$ & $(0.80)$ \\
\hline & \multicolumn{5}{|c|}{ Amstetten } \\
\hline & Pub & Restaurant & Coffeehouse & Carpenter & Bakery \\
\hline Log Likelihood & -361.23 & -150.76 & -296.41 & -125.36 & -126.42 \\
\hline No of Observations & 2407 & 996 & 2324 & 1411 & 1162 \\
\hline \multirow[t]{2}{*}{ Constant } & -19.91 & -15.41 & -16.41 & -6.64 & -7.74 \\
\hline & $(8.33)$ & $(11.33)$ & $(19.30)$ & $(8.96)$ & $(7.19)$ \\
\hline \multirow[t]{2}{*}{ Lagged Active } & 7.98 & 5.51 & 5.94 & 11.66 & 6.74 \\
\hline & $(0.89)$ & $(0.72)$ & $(0.36)$ & $(2.07)$ & $(1.04)$ \\
\hline \multirow[t]{2}{*}{ Number of Other Active Firms } & 0.09 & 0.10 & 0.08 & 0.35 & 0.20 \\
\hline & $(0.05)$ & (0.08) & $(0.03)$ & $(0.14)$ & $(0.10)$ \\
\hline \multirow[t]{2}{*}{ (Lagged Active)*(No of Other Active Firms) } & -0.22 & -0.27 & -0.15 & -0.59 & -0.33 \\
\hline & $(0.04)$ & $(0.09)$ & $(0.02)$ & $(0.15)$ & $(0.12)$ \\
\hline \multirow[t]{2}{*}{ Log GDP } & 1.30 & 1.03 & 1.05 & 0.03 & 0.33 \\
\hline & $(0.71)$ & $(0.92)$ & $(1.53)$ & $(0.75)$ & $(0.56)$ \\
\hline
\end{tabular}

* The dependent variable equals 1 if the firm is active and zero otherwise. Standard errors are displayed in parenthesis. 
Table III: Profit and Entry Cost Estimates in Baden

\begin{tabular}{|c|c|c|c|c|c|c|c|c|c|c|c|c|c|c|c|}
\hline \multirow[b]{2}{*}{$\begin{array}{c}\text { Number of Other } \\
\text { Active Firms } \\
\end{array}$} & \multicolumn{3}{|c|}{ Pub } & \multicolumn{3}{|c|}{ Restaurant } & \multicolumn{3}{|c|}{ Coffeehouse } & \multicolumn{3}{|c|}{ Carpenter } & \multicolumn{3}{|c|}{ Bakery } \\
\hline & $\begin{array}{l}\text { Entry } \\
\text { Cost }\end{array}$ & $\begin{array}{l}\text { High GDP } \\
\text { Profit }\end{array}$ & $\begin{array}{c}\text { Low GDP } \\
\text { Profit } \\
\end{array}$ & $\begin{array}{l}\text { Entry } \\
\text { Cost } \\
\end{array}$ & $\begin{array}{l}\text { High GDP } \\
\text { Profit }\end{array}$ & $\begin{array}{c}\text { Low GDP } \\
\text { Profit } \\
\end{array}$ & $\begin{array}{l}\text { Entry } \\
\text { Cost } \\
\end{array}$ & $\begin{array}{l}\text { High GDP } \\
\text { Profit }\end{array}$ & $\begin{array}{c}\text { Low GDP } \\
\text { Profit } \\
\end{array}$ & $\begin{array}{l}\text { Entry } \\
\text { Cost }\end{array}$ & $\begin{array}{l}\text { High GDP } \\
\text { Profit }\end{array}$ & $\begin{array}{c}\text { Low GDP } \\
\text { Profit }\end{array}$ & $\begin{array}{l}\text { Entry } \\
\text { Cost } \\
\end{array}$ & $\begin{array}{l}\text { High GDP } \\
\text { Profit }\end{array}$ & $\begin{array}{l}\text { Low GDP } \\
\text { Profit }\end{array}$ \\
\hline 0 & $\begin{array}{r}14.41 \\
(0.88)\end{array}$ & $\begin{array}{r}0.42 \\
(0.18)\end{array}$ & $\begin{array}{r}0.48 \\
(0.29)\end{array}$ & $\begin{array}{r}14.79 \\
(0.39)\end{array}$ & $\begin{array}{r}0.33 \\
(0.05)\end{array}$ & $\begin{array}{r}0.30 \\
(0.02)\end{array}$ & $\begin{array}{l}14.78 \\
(0.96)\end{array}$ & $\begin{array}{r}0.39 \\
(0.12)\end{array}$ & $\begin{array}{r}0.41 \\
(0.15)\end{array}$ & $\begin{array}{r}16.06 \\
(1.32)\end{array}$ & $\begin{array}{r}0.92 \\
(1.76)\end{array}$ & $\begin{array}{r}0.51 \\
(0.46)\end{array}$ & $\begin{array}{l}11.35 \\
(2.64)\end{array}$ & $\begin{array}{r}323520.90 \\
(7474945)\end{array}$ & $\begin{array}{r}3852868.80 \\
(101652130)\end{array}$ \\
\hline 1 & $\begin{array}{r}14.32 \\
(0.83)\end{array}$ & $\begin{array}{r}0.42 \\
(0.17)\end{array}$ & $\begin{array}{r}0.49 \\
(0.28)\end{array}$ & $\begin{array}{l}14.71 \\
(0.37)\end{array}$ & $\begin{array}{r}0.33 \\
(0.05)\end{array}$ & $\begin{array}{r}0.30 \\
(0.01)\end{array}$ & $\begin{array}{l}14.65 \\
(0.89)\end{array}$ & $\begin{array}{r}0.39 \\
(0.12)\end{array}$ & $\begin{array}{r}0.41 \\
(0.15)\end{array}$ & $\begin{array}{l}15.85 \\
(1.19)\end{array}$ & $\begin{array}{r}0.84 \\
(1.38)\end{array}$ & $\begin{array}{r}0.48 \\
(0.36)\end{array}$ & $\begin{array}{l}11.75 \\
(2.53)\end{array}$ & $\begin{array}{r}1906.56 \\
(27348.29)\end{array}$ & $\begin{array}{r}13183.76 \\
(221337.01)\end{array}$ \\
\hline 2 & $\begin{array}{l}14.23 \\
(0.78)\end{array}$ & $\begin{array}{r}0.42 \\
(0.17)\end{array}$ & $\begin{array}{r}0.49 \\
(0.27)\end{array}$ & $\begin{array}{l}14.64 \\
(0.34)\end{array}$ & $\begin{array}{r}0.33 \\
(0.05)\end{array}$ & $\begin{array}{r}0.30 \\
(0.01)\end{array}$ & $\begin{array}{l}14.51 \\
(0.82)\end{array}$ & $\begin{array}{r}0.39 \\
(0.12)\end{array}$ & $\begin{array}{r}0.42 \\
(0.14)\end{array}$ & $\begin{array}{l}15.63 \\
(1.07)\end{array}$ & $\begin{array}{r}0.77 \\
(1.07)\end{array}$ & $\begin{array}{r}0.46 \\
(0.27)\end{array}$ & $\begin{array}{l}12.16 \\
(2.24)\end{array}$ & $\begin{array}{r}46.37 \\
(434.04)\end{array}$ & $\begin{array}{r}194.96 \\
(2230.42)\end{array}$ \\
\hline 3 & $\begin{array}{r}14.14 \\
(0.72)\end{array}$ & $\begin{array}{r}0.41 \\
(0.16)\end{array}$ & $\begin{array}{r}0.49 \\
(0.26)\end{array}$ & $\begin{array}{r}14.56 \\
(0.31)\end{array}$ & $\begin{array}{r}0.33 \\
(0.05)\end{array}$ & $\begin{array}{r}0.30 \\
(0.01)\end{array}$ & $\begin{array}{l}14.37 \\
(0.75)\end{array}$ & $\begin{array}{r}0.40 \\
(0.11)\end{array}$ & $\begin{array}{r}0.42 \\
(0.14)\end{array}$ & $\begin{array}{l}15.42 \\
(0.95)\end{array}$ & $\begin{array}{r}0.71 \\
(0.81)\end{array}$ & $\begin{array}{r}0.43 \\
(0.20)\end{array}$ & $\begin{array}{l}12.53 \\
(1.81)\end{array}$ & $\begin{array}{r}3.88 \\
(18.56)\end{array}$ & $\begin{array}{r}9.48 \\
(62.49)\end{array}$ \\
\hline 4 & $\begin{array}{l}14.05 \\
(0.67)\end{array}$ & $\begin{array}{r}0.41 \\
(0.15)\end{array}$ & $\begin{array}{r}0.49 \\
(0.25)\end{array}$ & $\begin{array}{l}14.48 \\
(0.29)\end{array}$ & $\begin{array}{r}0.33 \\
(0.05)\end{array}$ & $\begin{array}{r}0.30 \\
(0.01)\end{array}$ & $\begin{array}{l}14.24 \\
(0.68)\end{array}$ & $\begin{array}{r}0.40 \\
(0.11)\end{array}$ & $\begin{array}{r}0.42 \\
(0.13)\end{array}$ & $\begin{array}{l}15.21 \\
(0.83)\end{array}$ & $\begin{array}{r}0.65 \\
(0.61)\end{array}$ & $\begin{array}{r}0.41 \\
(0.15)\end{array}$ & $\begin{array}{l}12.85 \\
(1.39)\end{array}$ & $\begin{array}{r}1.08 \\
(1.99)\end{array}$ & $\begin{array}{r}1.66 \\
(4.52)\end{array}$ \\
\hline 5 & $\begin{array}{r}13.96 \\
(0.62)\end{array}$ & $\begin{array}{r}0.41 \\
(0.14)\end{array}$ & $\begin{array}{r}0.49 \\
(0.23)\end{array}$ & $\begin{array}{r}14.40 \\
(0.26)\end{array}$ & $\begin{array}{r}0.33 \\
(0.05)\end{array}$ & $\begin{array}{r}0.29 \\
(0.01)\end{array}$ & $\begin{array}{l}14.10 \\
(0.61)\end{array}$ & $\begin{array}{r}0.40 \\
(0.10)\end{array}$ & $\begin{array}{r}0.43 \\
(0.12)\end{array}$ & $\begin{array}{l}14.99 \\
(0.72)\end{array}$ & $\begin{array}{r}0.60 \\
(0.45)\end{array}$ & $\begin{array}{r}0.39 \\
(0.10)\end{array}$ & $\begin{array}{l}13.12 \\
(1.02)\end{array}$ & $\begin{array}{r}0.60 \\
(0.43)\end{array}$ & $\begin{array}{r}0.75 \\
(0.76)\end{array}$ \\
\hline 6 & $\begin{array}{r}13.87 \\
(0.57)\end{array}$ & $\begin{array}{r}0.41 \\
(0.13)\end{array}$ & $\begin{array}{r}0.49 \\
(0.22)\end{array}$ & $\begin{array}{c}14.33 \\
(0.24)\end{array}$ & $\begin{array}{r}0.33 \\
(0.04)\end{array}$ & $\begin{array}{r}0.29 \\
(0.01)\end{array}$ & $\begin{array}{r}13.96 \\
(0.54)\end{array}$ & $\begin{array}{r}0.40 \\
(0.10)\end{array}$ & $\begin{array}{r}0.43 \\
(0.12)\end{array}$ & $\begin{array}{r}14.78 \\
(0.60)\end{array}$ & $\begin{array}{r}0.55 \\
(0.32)\end{array}$ & $\begin{array}{r}0.37 \\
(0.07)\end{array}$ & $\begin{array}{l}13.36 \\
(0.71)\end{array}$ & $\begin{array}{r}0.43 \\
(0.13)\end{array}$ & $\begin{array}{r}0.50 \\
(0.21)\end{array}$ \\
\hline 7 & $\begin{array}{r}13.78 \\
(0.51)\end{array}$ & $\begin{array}{r}0.41 \\
(0.12)\end{array}$ & $\begin{array}{r}0.48 \\
(0.21)\end{array}$ & $\begin{array}{r}14.25 \\
(0.22)\end{array}$ & $\begin{array}{r}0.33 \\
(0.04)\end{array}$ & $\begin{array}{r}0.29 \\
(0.02)\end{array}$ & $\begin{array}{r}13.82 \\
(0.47)\end{array}$ & $\begin{array}{r}0.40 \\
(0.09)\end{array}$ & $\begin{array}{r}0.43 \\
(0.11)\end{array}$ & $\begin{array}{l}14.57 \\
(0.49)\end{array}$ & $\begin{array}{r}0.51 \\
(0.22)\end{array}$ & $\begin{array}{r}0.35 \\
(0.05)\end{array}$ & $\begin{array}{l}13.59 \\
(0.43)\end{array}$ & $\begin{array}{r}0.36 \\
(0.04)\end{array}$ & $\begin{array}{r}0.40 \\
(0.07)\end{array}$ \\
\hline 8 & $\begin{array}{l}13.69 \\
(0.46)\end{array}$ & $\begin{array}{r}0.41 \\
(0.11)\end{array}$ & $\begin{array}{r}0.48 \\
(0.19)\end{array}$ & $\begin{array}{r}14.17 \\
(0.19)\end{array}$ & $\begin{array}{r}0.33 \\
(0.04)\end{array}$ & $\begin{array}{r}0.29 \\
(0.02)\end{array}$ & $\begin{array}{l}13.69 \\
(0.40)\end{array}$ & $\begin{array}{r}0.40 \\
(0.08)\end{array}$ & $\begin{array}{r}0.43 \\
(0.10)\end{array}$ & $\begin{array}{l}14.35 \\
(0.39)\end{array}$ & $\begin{array}{r}0.47 \\
(0.15)\end{array}$ & $\begin{array}{r}0.32 \\
(0.04)\end{array}$ & $\begin{array}{l}13.80 \\
(0.23)\end{array}$ & $\begin{array}{r}0.32 \\
(0.01)\end{array}$ & $\begin{array}{r}0.35 \\
(0.03)\end{array}$ \\
\hline 9 & $\begin{array}{r}13.60 \\
(0.41)\end{array}$ & $\begin{array}{r}0.40 \\
(0.10)\end{array}$ & $\begin{array}{r}0.48 \\
(0.18)\end{array}$ & $\begin{array}{r}14.09 \\
(0.17)\end{array}$ & $\begin{array}{r}0.33 \\
(0.04)\end{array}$ & $\begin{array}{r}0.28 \\
(0.03)\end{array}$ & $\begin{array}{l}13.55 \\
(0.33)\end{array}$ & $\begin{array}{r}0.39 \\
(0.07)\end{array}$ & $\begin{array}{r}0.43 \\
(0.09)\end{array}$ & $\begin{array}{c}14.14 \\
(0.29)\end{array}$ & $\begin{array}{r}0.43 \\
(0.09)\end{array}$ & $\begin{array}{r}0.28 \\
(0.05)\end{array}$ & $\begin{array}{l}14.01 \\
(0.29)\end{array}$ & $\begin{array}{r}0.30 \\
(0.03)\end{array}$ & $\begin{array}{r}0.32 \\
(0.03)\end{array}$ \\
\hline 10 & $\begin{array}{l}13.51 \\
(0.36)\end{array}$ & $\begin{array}{r}0.40 \\
(0.09)\end{array}$ & $\begin{array}{r}0.48 \\
(0.16)\end{array}$ & $\begin{array}{r}14.02 \\
(0.15)\end{array}$ & $\begin{array}{r}0.33 \\
(0.03)\end{array}$ & $\begin{array}{r}0.28 \\
(0.03)\end{array}$ & $\begin{array}{l}13.41 \\
(0.27)\end{array}$ & $\begin{array}{r}0.39 \\
(0.06)\end{array}$ & $\begin{array}{r}0.43 \\
(0.08)\end{array}$ & $\begin{array}{l}13.92 \\
(0.21)\end{array}$ & $\begin{array}{r}0.39 \\
(0.05)\end{array}$ & $\begin{array}{r}0.22 \\
(0.11)\end{array}$ & $\begin{array}{l}14.22 \\
(0.52)\end{array}$ & $\begin{array}{r}0.28 \\
(0.05)\end{array}$ & $\begin{array}{r}0.30 \\
(0.05)\end{array}$ \\
\hline 11 & $\begin{array}{r}13.42 \\
(0.31)\end{array}$ & $\begin{array}{r}0.39 \\
(0.08)\end{array}$ & $\begin{array}{r}0.47 \\
(0.15)\end{array}$ & $\begin{array}{c}13.94 \\
(0.14)\end{array}$ & $\begin{array}{r}0.33 \\
(0.03)\end{array}$ & $\begin{array}{r}0.28 \\
(0.04)\end{array}$ & $\begin{array}{l}13.27 \\
(0.20)\end{array}$ & $\begin{array}{r}0.38 \\
(0.05)\end{array}$ & $\begin{array}{r}0.42 \\
(0.06)\end{array}$ & $\begin{array}{l}13.69 \\
(0.18)\end{array}$ & $\begin{array}{r}0.33 \\
(0.03)\end{array}$ & $\begin{array}{r}0.09 \\
(0.28)\end{array}$ & & & \\
\hline 12 & $\begin{array}{r}13.33 \\
(0.26)\end{array}$ & $\begin{array}{r}0.39 \\
(0.07)\end{array}$ & $\begin{array}{r}0.47 \\
(0.13)\end{array}$ & $\begin{array}{r}13.86 \\
(0.13)\end{array}$ & $\begin{array}{r}0.33 \\
(0.02)\end{array}$ & $\begin{array}{r}0.27 \\
(0.05)\end{array}$ & $\begin{array}{r}13.13 \\
(0.15)\end{array}$ & $\begin{array}{r}0.37 \\
(0.04)\end{array}$ & $\begin{array}{r}0.41 \\
(0.06)\end{array}$ & $\begin{array}{l}13.45 \\
(0.23)\end{array}$ & $\begin{array}{r}0.25 \\
(0.09)\end{array}$ & $\begin{array}{r}-0.18 \\
(0.80)\end{array}$ & & & \\
\hline 13 & $\begin{array}{c}13.24 \\
(0.21)\end{array}$ & $\begin{array}{r}0.38 \\
(0.06)\end{array}$ & $\begin{array}{r}0.46 \\
(0.12)\end{array}$ & $\begin{array}{c}13.78 \\
(0.12)\end{array}$ & $\begin{array}{r}0.33 \\
(0.02)\end{array}$ & $\begin{array}{r}0.27 \\
(0.06)\end{array}$ & $\begin{array}{l}12.99 \\
(0.12)\end{array}$ & $\begin{array}{r}0.36 \\
(0.03)\end{array}$ & $\begin{array}{r}0.40 \\
(0.05)\end{array}$ & $\begin{array}{l}13.19 \\
(0.36)\end{array}$ & $\begin{array}{r}0.10 \\
(0.27)\end{array}$ & $\begin{array}{r}-0.98 \\
(3.11)\end{array}$ & & & \\
\hline 14 & $\begin{array}{r}13.15 \\
(0.17)\end{array}$ & $\begin{array}{r}0.37 \\
(0.04)\end{array}$ & $\begin{array}{r}0.45 \\
(0.10)\end{array}$ & $\begin{array}{r}13.71 \\
(0.12)\end{array}$ & $\begin{array}{r}0.32 \\
(0.01)\end{array}$ & $\begin{array}{r}0.27 \\
(0.07)\end{array}$ & $\begin{array}{l}12.85 \\
(0.12)\end{array}$ & $\begin{array}{r}0.33 \\
(0.03)\end{array}$ & $\begin{array}{r}0.38 \\
(0.05)\end{array}$ & $\begin{array}{l}12.88 \\
(0.60)\end{array}$ & $\begin{array}{l}-0.27 \\
(0.95)\end{array}$ & $\begin{array}{r}-4.88 \\
(20.97)\end{array}$ & & & \\
\hline 15 & $\begin{array}{l}13.06 \\
(0.13)\end{array}$ & $\begin{array}{r}0.35 \\
(0.03)\end{array}$ & $\begin{array}{r}0.44 \\
(0.09)\end{array}$ & $\begin{array}{l}13.63 \\
(0.13)\end{array}$ & $\begin{array}{r}0.32 \\
(0.01)\end{array}$ & $\begin{array}{r}0.26 \\
(0.09)\end{array}$ & $\begin{array}{l}12.71 \\
(0.17)\end{array}$ & $\begin{array}{r}0.30 \\
(0.06)\end{array}$ & $\begin{array}{r}0.35 \\
(0.07)\end{array}$ & & & & & & \\
\hline 16 & $\begin{array}{r}12.96 \\
(0.11)\end{array}$ & $\begin{array}{r}0.34 \\
(0.02)\end{array}$ & $\begin{array}{r}0.43 \\
(0.07)\end{array}$ & $\begin{array}{l}13.55 \\
(0.14)\end{array}$ & $\begin{array}{r}0.32 \\
(0.02)\end{array}$ & $\begin{array}{r}0.25 \\
(0.11)\end{array}$ & $\begin{array}{l}12.57 \\
(0.24)\end{array}$ & $\begin{array}{r}0.25 \\
(0.11)\end{array}$ & $\begin{array}{r}0.31 \\
(0.10)\end{array}$ & & & & & & \\
\hline 17 & $\begin{array}{r}12.87 \\
(0.11)\end{array}$ & $\begin{array}{r}0.32 \\
(0.03)\end{array}$ & $\begin{array}{r}0.41 \\
(0.06)\end{array}$ & $\begin{array}{l}13.47 \\
(0.15)\end{array}$ & $\begin{array}{r}0.32 \\
(0.03)\end{array}$ & $\begin{array}{r}0.25 \\
(0.13)\end{array}$ & $\begin{array}{l}12.42 \\
(0.31)\end{array}$ & $\begin{array}{r}0.16 \\
(0.23)\end{array}$ & $\begin{array}{r}0.24 \\
(0.19)\end{array}$ & & & & & & \\
\hline 18 & $\begin{array}{l}12.78 \\
(0.14)\end{array}$ & $\begin{array}{r}0.29 \\
(0.05)\end{array}$ & $\begin{array}{r}0.39 \\
(0.05)\end{array}$ & $\begin{array}{l}13.40 \\
(0.17)\end{array}$ & $\begin{array}{r}0.31 \\
(0.04)\end{array}$ & $\begin{array}{r}0.24 \\
(0.15)\end{array}$ & & & & & & & & & \\
\hline 19 & $\begin{array}{r}12.69 \\
(0.18)\end{array}$ & $\begin{array}{r}0.26 \\
(0.09)\end{array}$ & $\begin{array}{r}0.37 \\
(0.05)\end{array}$ & $\begin{array}{r}13.32 \\
(0.19)\end{array}$ & $\begin{array}{r}0.31 \\
(0.05)\end{array}$ & $\begin{array}{r}0.23 \\
(0.18)\end{array}$ & & & & & & & & & \\
\hline 20 & $\begin{array}{r}12.60 \\
(0.23)\end{array}$ & $\begin{array}{r}0.22 \\
(0.14)\end{array}$ & $\begin{array}{r}0.34 \\
(0.07)\end{array}$ & $\begin{array}{l}13.24 \\
(0.22)\end{array}$ & $\begin{array}{r}0.31 \\
(0.07)\end{array}$ & $\begin{array}{r}0.22 \\
(0.21)\end{array}$ & & & & & & & & & \\
\hline 21 & $\begin{array}{r}12.50 \\
(0.28)\end{array}$ & $\begin{array}{r}0.16 \\
(0.23)\end{array}$ & $\begin{array}{r}0.30 \\
(0.11)\end{array}$ & $\begin{array}{l}13.16 \\
(0.24)\end{array}$ & $\begin{array}{r}0.30 \\
(0.09)\end{array}$ & $\begin{array}{r}0.21 \\
(0.25)\end{array}$ & & & & & & & & & \\
\hline 22 & & & & $\begin{array}{l}13.08 \\
(0.27)\end{array}$ & $\begin{array}{r}0.29 \\
(0.11)\end{array}$ & $\begin{array}{r}0.19 \\
(0.30)\end{array}$ & & & & & & & & & \\
\hline 23 & & & & $\begin{array}{l}13.01 \\
(0.29)\end{array}$ & $\begin{array}{r}0.28 \\
(0.14)\end{array}$ & $\begin{array}{r}0.17 \\
(0.35)\end{array}$ & & & & & & & & & \\
\hline 24 & & & & $\begin{array}{l}12.93 \\
(0.32)\end{array}$ & $\begin{array}{r}0.27 \\
(0.17)\end{array}$ & $\begin{array}{r}0.15 \\
(0.42)\end{array}$ & & & & & & & & & \\
\hline
\end{tabular}


Table IV: Profit and Entry Cost Estimates in Amstetten

\section{Pub \\ Restaurant \\ Coffeehouse}

Carpenter

Bakery

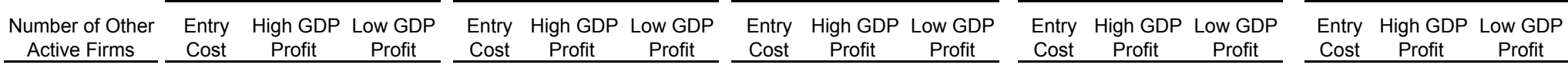

\begin{tabular}{|c|c|c|c|c|c|c|c|c|c|c|c|c|c|c|c|}
\hline Active Firms & Cost & Profit & Profit & Cost & Profit & Profit & Cost & Profit & Profit & Cost & Profit & Profit & Cost & Profit & Profit \\
\hline 0 & $\begin{array}{c}17.98 \\
(0.89)\end{array}$ & $\begin{array}{r}0.37 \\
(0.03)\end{array}$ & $\begin{array}{r}0.36 \\
(0.02)\end{array}$ & $\begin{array}{l}15.52 \\
(0.72)\end{array}$ & $\begin{array}{r}0.37 \\
(0.09)\end{array}$ & $\begin{array}{r}0.34 \\
(0.04)\end{array}$ & $\begin{array}{l}15.94 \\
(0.36)\end{array}$ & $\begin{array}{r}0.33 \\
(0.02)\end{array}$ & $\begin{array}{r}0.32 \\
(0.01)\end{array}$ & $\begin{array}{l}21.66 \\
(2.27)\end{array}$ & $\begin{array}{r}0.38 \\
(0.03)\end{array}$ & $\begin{array}{r}0.38 \\
(0.03)\end{array}$ & $\begin{array}{l}16.74 \\
(1.04)\end{array}$ & $\begin{array}{r}0.33 \\
(0.01)\end{array}$ & $\begin{array}{r}0.33 \\
(0.01)\end{array}$ \\
\hline \multirow[t]{2}{*}{1} & 17.77 & 0.37 & 0.35 & 15.25 & 0.37 & 0.34 & 15.79 & 0.33 & 0.31 & 21.07 & 0.38 & 0.38 & 16.41 & 0.33 & 0.32 \\
\hline & $(0.84)$ & $(0.03)$ & $(0.02)$ & $(0.64)$ & $(0.09)$ & $(0.04)$ & $(0.34)$ & $(0.02)$ & $(0.01)$ & $(1.91)$ & $(0.03)$ & $(0.02)$ & (0.93) & $(0.01)$ & $(0.01)$ \\
\hline \multirow[t]{2}{*}{2} & 17.55 & 0.37 & 0.35 & 14.98 & 0.38 & 0.34 & 15.64 & 0.33 & 0.31 & 20.49 & 0.37 & 0.37 & 16.08 & 0.32 & 0.32 \\
\hline & $(0.80)$ & $(0.03)$ & $(0.02)$ & $(0.56)$ & $(0.09)$ & $(0.04)$ & $(0.33)$ & $(0.03)$ & $(0.01)$ & $(1.77)$ & $(0.02)$ & $(0.02)$ & $(0.81)$ & $(0.01)$ & $(0.01)$ \\
\hline \multirow[t]{2}{*}{3} & 17.33 & 0.36 & 0.35 & 14.71 & 0.38 & 0.34 & 15.49 & 0.33 & 0.31 & 19.90 & 0.37 & 0.37 & 15.75 & 0.32 & 0.32 \\
\hline & $(0.76)$ & $(0.03)$ & $(0.02)$ & $(0.48)$ & $(0.09)$ & $(0.03)$ & $(0.31)$ & $(0.03)$ & $(0.01)$ & $(1.62)$ & $(0.02)$ & $(0.02)$ & $(0.70)$ & $(0.01)$ & $(0.01)$ \\
\hline \multirow[t]{2}{*}{4} & 17.11 & 0.36 & 0.34 & 14.43 & 0.38 & 0.34 & 15.33 & 0.32 & 0.31 & 19.32 & 0.36 & 0.36 & 15.43 & 0.32 & 0.31 \\
\hline & $(0.72)$ & $(0.04)$ & $(0.02)$ & $(0.40)$ & $(0.08)$ & $(0.03)$ & $(0.29)$ & $(0.03)$ & $(0.01)$ & $(1.47)$ & $(0.02)$ & $(0.02)$ & (0.58) & $(0.01)$ & $(0.01)$ \\
\hline 5 & $\begin{array}{l}16.89 \\
(0.68)\end{array}$ & $\begin{array}{r}0.36 \\
(0.04)\end{array}$ & $\begin{array}{r}0.34 \\
(0.02)\end{array}$ & $\begin{array}{l}14.16 \\
(0.32)\end{array}$ & $\begin{array}{r}0.39 \\
(0.08)\end{array}$ & $\begin{array}{r}0.33 \\
(0.03)\end{array}$ & $\begin{array}{l}15.18 \\
(0.27)\end{array}$ & $\begin{array}{r}0.33 \\
(0.04)\end{array}$ & $\begin{array}{r}0.31 \\
(0.01)\end{array}$ & $\begin{array}{r}18.73 \\
(1.32)\end{array}$ & $\begin{array}{r}0.35 \\
(0.02)\end{array}$ & $\begin{array}{r}0.35 \\
(0.02)\end{array}$ & $\begin{array}{l}15.10 \\
(0.47)\end{array}$ & $\begin{array}{r}0.32 \\
(0.02)\end{array}$ & $\begin{array}{r}0.31 \\
(0.02)\end{array}$ \\
\hline 6 & $\begin{array}{l}16.67 \\
(0.64)\end{array}$ & $\begin{array}{r}0.36 \\
(0.04)\end{array}$ & $\begin{array}{r}0.34 \\
(0.02)\end{array}$ & $\begin{array}{l}13.89 \\
(0.25)\end{array}$ & $\begin{array}{r}0.38 \\
(0.06)\end{array}$ & $\begin{array}{r}0.32 \\
(0.04)\end{array}$ & $\begin{array}{l}15.03 \\
(0.26)\end{array}$ & $\begin{array}{r}0.33 \\
(0.04)\end{array}$ & $\begin{array}{r}0.31 \\
(0.02)\end{array}$ & $\begin{array}{c}18.14 \\
(1.17)\end{array}$ & $\begin{array}{r}0.35 \\
(0.02)\end{array}$ & $\begin{array}{r}0.35 \\
(0.01)\end{array}$ & $\begin{array}{l}14.77 \\
(0.37)\end{array}$ & $\begin{array}{r}0.31 \\
(0.02)\end{array}$ & $\begin{array}{r}0.31 \\
(0.02)\end{array}$ \\
\hline \multirow[t]{2}{*}{7} & 16.45 & 0.36 & 0.34 & 13.62 & 0.38 & 0.30 & 14.88 & 0.33 & 0.31 & 17.56 & 0.34 & 0.34 & 14.44 & 0.31 & 0.30 \\
\hline & $(0.60)$ & $(0.05)$ & $(0.02)$ & $(0.19)$ & $(0.05)$ & $(0.06)$ & $(0.24)$ & $(0.04)$ & $(0.02)$ & $(1.02)$ & $(0.01)$ & $(0.01)$ & $(0.27)$ & $(0.02)$ & $(0.02)$ \\
\hline \multirow[t]{2}{*}{8} & 16.23 & 0.36 & 0.33 & 13.34 & 0.37 & 0.27 & 14.73 & 0.33 & 0.30 & 16.97 & 0.34 & 0.34 & 14.12 & 0.31 & 0.30 \\
\hline & $(0.56)$ & $(0.05)$ & $(0.02)$ & $(0.16)$ & $(0.03)$ & $(0.10)$ & $(0.22)$ & $(0.04)$ & $(0.02)$ & $(0.86)$ & $(0.01)$ & $(0.01)$ & (0.19) & $(0.02)$ & $(0.02)$ \\
\hline \multirow[t]{2}{*}{9} & 16.02 & 0.36 & 0.33 & 13.06 & 0.33 & 0.21 & 14.58 & 0.33 & 0.30 & 16.39 & 0.33 & 0.33 & 13.79 & 0.31 & 0.29 \\
\hline & $(0.52)$ & $(0.06)$ & $(0.02)$ & $(0.18)$ & $(0.04)$ & $(0.19)$ & $(0.21)$ & $(0.04)$ & $(0.03)$ & $(0.72)$ & $(0.01)$ & $(0.01)$ & $(0.16)$ & $(0.02)$ & $(0.04)$ \\
\hline 10 & $\begin{array}{l}15.80 \\
(0.48)\end{array}$ & $\begin{array}{r}0.36 \\
(0.06)\end{array}$ & $\begin{array}{r}0.33 \\
(0.02)\end{array}$ & $\begin{array}{l}12.77 \\
(0.24)\end{array}$ & $\begin{array}{r}0.27 \\
(0.11)\end{array}$ & $\begin{array}{r}0.10 \\
(0.37)\end{array}$ & $\begin{array}{c}14.42 \\
(0.19)\end{array}$ & $\begin{array}{r}0.33 \\
(0.05)\end{array}$ & $\begin{array}{r}0.30 \\
(0.03)\end{array}$ & $\begin{array}{l}15.81 \\
(0.57)\end{array}$ & $\begin{array}{r}0.33 \\
(0.01)\end{array}$ & $\begin{array}{r}0.33 \\
(0.01)\end{array}$ & $\begin{array}{r}13.46 \\
(0.21)\end{array}$ & $\begin{array}{r}0.31 \\
(0.03)\end{array}$ & $\begin{array}{r}0.28 \\
(0.06)\end{array}$ \\
\hline 11 & $\begin{array}{l}15.58 \\
(0.44)\end{array}$ & $\begin{array}{r}0.36 \\
(0.07)\end{array}$ & $\begin{array}{r}0.33 \\
(0.02)\end{array}$ & $\begin{array}{l}12.47 \\
(0.34)\end{array}$ & $\begin{array}{r}0.12 \\
(0.30)\end{array}$ & $\begin{array}{r}-0.18 \\
(0.93)\end{array}$ & $\begin{array}{l}14.27 \\
(0.18)\end{array}$ & $\begin{array}{r}0.34 \\
(0.05)\end{array}$ & $\begin{array}{r}0.30 \\
(0.04)\end{array}$ & $\begin{array}{l}15.22 \\
(0.43)\end{array}$ & $\begin{array}{r}0.32 \\
(0.02)\end{array}$ & $\begin{array}{r}0.32 \\
(0.02)\end{array}$ & $\begin{array}{l}13.12 \\
(0.30)\end{array}$ & $\begin{array}{r}0.30 \\
(0.06)\end{array}$ & $\begin{array}{r}0.26 \\
(0.10)\end{array}$ \\
\hline \multirow[t]{2}{*}{12} & 15.36 & 0.37 & 0.33 & & & & 14.12 & 0.34 & 0.30 & 14.64 & 0.32 & 0.32 & 12.78 & 0.27 & 0.22 \\
\hline & $(0.40)$ & $(0.07)$ & $(0.02)$ & & & & $(0.16)$ & $(0.04)$ & $(0.06)$ & $(0.30)$ & $(0.04)$ & $(0.03)$ & $(0.41)$ & $(0.12)$ & $(0.19)$ \\
\hline \multirow[t]{2}{*}{13} & 15.14 & 0.37 & 0.32 & & & & 13.97 & 0.34 & 0.29 & 14.06 & 0.34 & 0.34 & 12.43 & 0.16 & 0.08 \\
\hline & $(0.36)$ & $(0.07)$ & $(0.02)$ & & & & $(0.15)$ & $(0.04)$ & $(0.07)$ & $(0.20)$ & $(0.04)$ & $(0.04)$ & (0.56) & $(0.28)$ & $(0.42)$ \\
\hline \multirow[t]{2}{*}{14} & 14.92 & 0.37 & 0.32 & & & & 13.82 & 0.35 & 0.29 & 13.46 & 0.33 & 0.33 & & & \\
\hline & $(0.32)$ & $(0.07)$ & $(0.02)$ & & & & $(0.14)$ & $(0.04)$ & $(0.09)$ & $(0.19)$ & $(0.03)$ & $(0.08)$ & & & \\
\hline \multirow[t]{2}{*}{15} & 14.70 & 0.38 & 0.32 & & & & 13.66 & 0.35 & 0.29 & 12.86 & 0.41 & 0.40 & & & \\
\hline & $(0.29)$ & $(0.07)$ & $(0.02)$ & & & & $(0.13)$ & $(0.03)$ & $(0.11)$ & $(0.25)$ & $(0.22)$ & $(0.28)$ & & & \\
\hline 16 & 14.48 & 0.38 & 0.31 & & & & 13.51 & 0.36 & 0.28 & 12.08 & -0.14 & -0.16 & & & \\
\hline & $(0.25)$ & $(0.07)$ & $(0.02)$ & & & & $(0.12)$ & $(0.03)$ & $(0.14)$ & $(0.61)$ & $(0.84)$ & (1.16) & & & \\
\hline 17 & 14.26 & 0.38 & 0.30 & & & & 13.36 & 0.36 & 0.27 & & & & & & \\
\hline & $(0.21)$ & $(0.07)$ & $(0.03)$ & & & & $(0.12)$ & $(0.02)$ & $(0.18)$ & & & & & & \\
\hline 18 & 14.04 & 0.38 & 0.28 & & & & 13.20 & 0.36 & 0.26 & & & & & & \\
\hline & $(0.18)$ & $(0.06)$ & $(0.04)$ & & & & $(0.12)$ & $(0.02)$ & $(0.22)$ & & & & & & \\
\hline 19 & 13.82 & 0.38 & 0.26 & & & & 13.05 & 0.36 & 0.24 & & & & & & \\
\hline & $(0.15)$ & $(0.05)$ & $(0.06)$ & & & & $(0.12)$ & $(0.04)$ & $(0.28)$ & & & & & & \\
\hline 20 & 13.60 & 0.38 & 0.22 & & & & 12.90 & 0.36 & 0.22 & & & & & & \\
\hline & $(0.12)$ & $(0.04)$ & $(0.11)$ & & & & $(0.12)$ & $(0.06)$ & $(0.36)$ & & & & & & \\
\hline 21 & 13.38 & 0.37 & 0.16 & & & & 12.74 & 0.36 & 0.20 & & & & & & \\
\hline & $(0.11)$ & $(0.03)$ & $(0.19)$ & & & & $(0.13)$ & $(0.09)$ & $(0.46)$ & & & & & & \\
\hline 22 & 13.15 & 0.34 & 0.05 & & & & 12.59 & 0.35 & 0.16 & & & & & & \\
\hline & $(0.11)$ & $(0.03)$ & $(0.35)$ & & & & $(0.14)$ & $(0.13)$ & (0.61) & & & & & & \\
\hline 23 & 12.91 & 0.31 & 12.85 & & & & 12.43 & 0.33 & 0.09 & & & & & & \\
\hline & $(0.13)$ & $(0.09)$ & $(0.20)$ & & & & $(0.16)$ & $(0.19)$ & $(0.85)$ & & & & & & \\
\hline 24 & 12.67 & 0.16 & 12.58 & & & & 12.27 & 0.30 & 0.00 & & & & & & \\
\hline & $(0.17)$ & $(0.35)$ & $(0.31)$ & & & & $(0.17)$ & $(0.27)$ & $(1.22)$ & & & & & & \\
\hline 25 & 12.42 & 0.31 & 12.26 & & & & 12.11 & 0.21 & -0.26 & & & & & & \\
\hline & $(0.23)$ & (1.01) & $(0.52)$ & & & & $(0.19)$ & $(0.47)$ & (2.45) & & & & & & \\
\hline 26 & 12.13 & -1.45 & 11.84 & & & & 11.95 & 0.16 & -0.44 & & & & & & \\
\hline & $(0.35)$ & (5.65) & $(1.02)$ & & & & $(0.22)$ & $(0.57)$ & (3.07) & & & & & & \\
\hline 27 & 11.77 & 4.05 & 11.23 & & & & 11.77 & -0.69 & -5.22 & & & & & & \\
\hline & $(0.57)$ & $(20.92)$ & $(2.02)$ & & & & $(0.26)$ & (3.13) & $(39.26)$ & & & & & & \\
\hline 28 & 11.11 & $\begin{array}{r}-39.00 \\
147.371\end{array}$ & 9.56 & & & & & & & & & & & & \\
\hline
\end{tabular}

* Standard deviations are displayed in parenthesis. 
FIGURE 1: Value Function, Inactive, High GDP



FIGURE 3: Value Function, Inactive, Low GDP

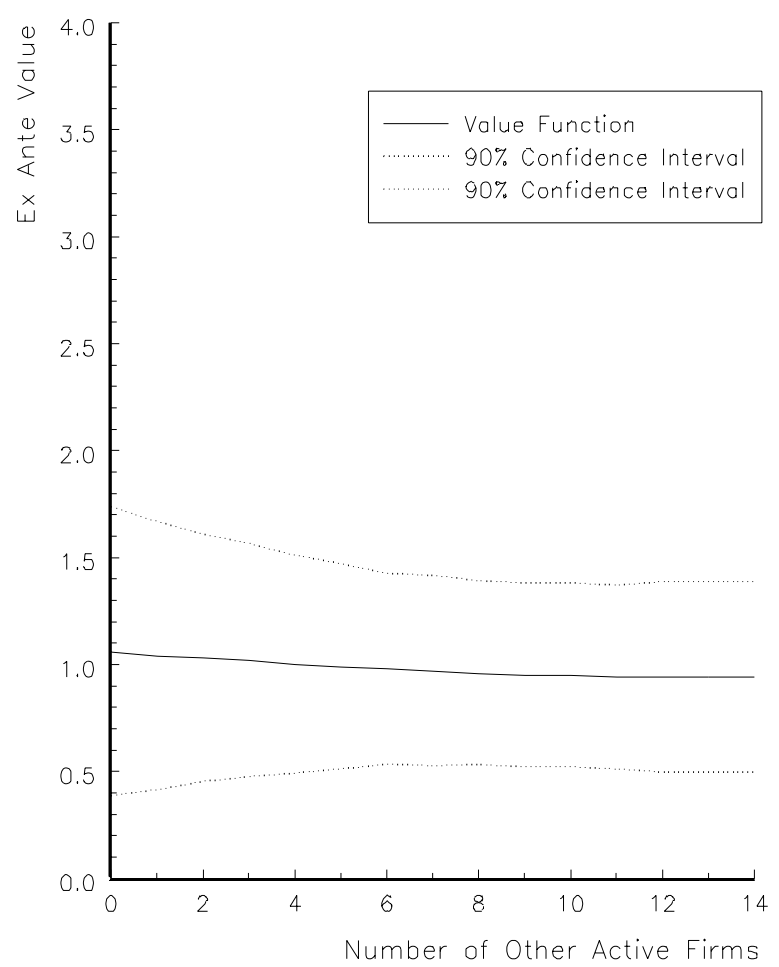

FIGURE 2: Value Function, Active, High GDP

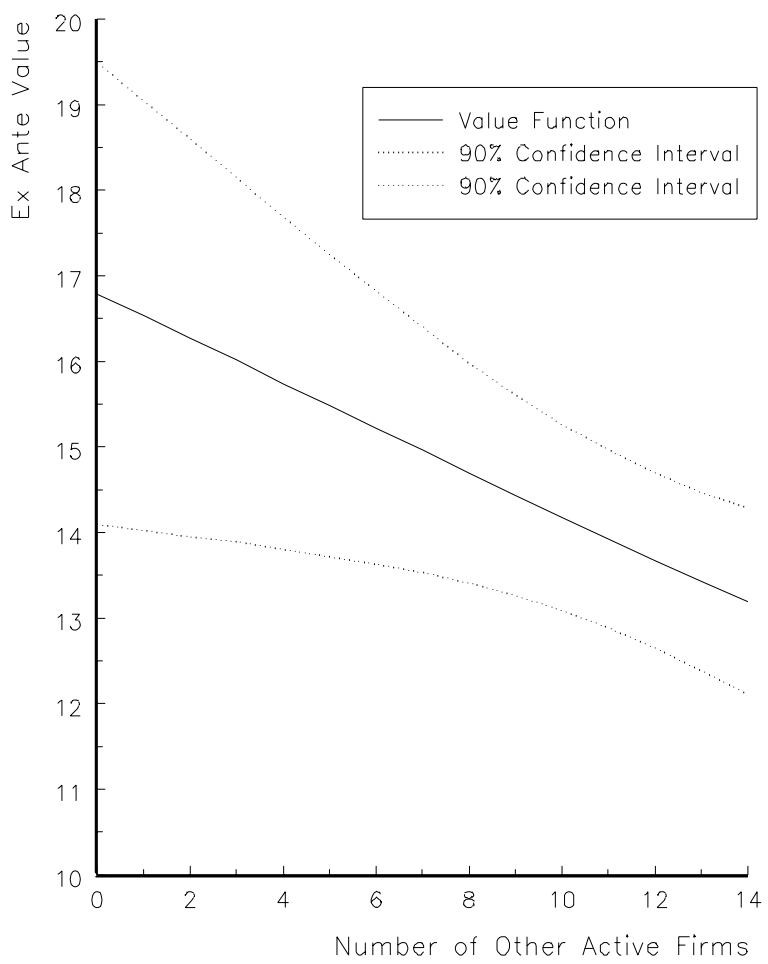

FIGURE 4: Value Function. Active, Low GDP

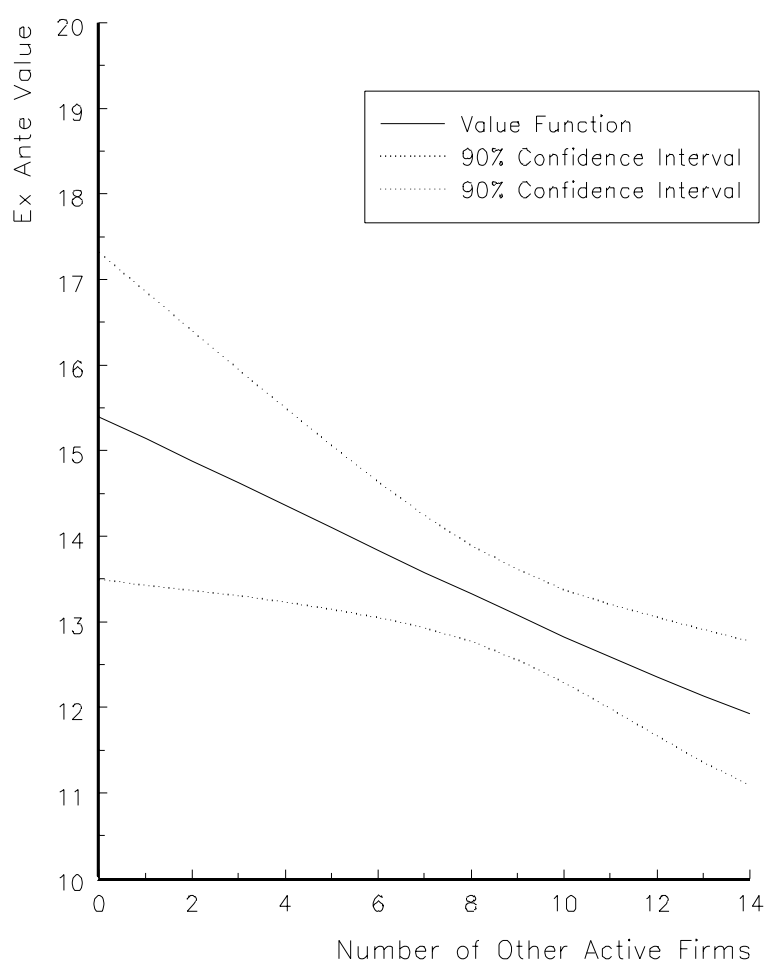

